\title{
Climatic niche comparison between closely related trans- Palearctic species of the genus Orthocephalus (Insecta: Heteroptera: Miridae: Orthotylinae)
}

\author{
Anna A Namyatova ${ }^{\text {Corresp. 1,2 }}$ \\ 1 Laboratory of Phytosanitary Diagnostics and Forecasts, All-Russian Institute of Plant Protection, St Petersburg, St Petersburg, Russia \\ 2 Laboratory of Insect Taxonomy, Zoological Institute, Russian Academy of Sciences, St Petersburg, St Petersburg, Russia \\ Corresponding Author: Anna A Namyatova \\ Email address: anna.namyatova@zin.ru
}

Previously climatic niche modelling had been studied for only a few trans-Palearctic species. It is unclear whether and to what extent those niches are different, and which climatic variables influence such a wide distribution. Here, environmental niche modelling is performed based on the Worldclim variables using Maxent for eight species of the genus Orthocephalus (Insecta: Heteroptera: Miridae: Orthotylinae). This group belongs to one of the largest insect families and it is distributed across Palearctic. Orthocephalus bivittatus, O. brevis, $O$. saltator and 0 . vittipennis are distributed across Europe and Asia; $O$. coriaceus, $O$. fulvipes, $O$. funesuts, $O$. proserpinae have more limited distribution. Niche comparison using ENMTools was also undertaken to compare the niches of these species, and to test whether the niches of closely related species with trans-Palearctic distributions are more similar to each other, than to other congeners. It has been found that climatic niche models of all trans-Palearctic species under study are similar but are not identical to each other. This has been supported by niche geographic projections, climatic variables contributing to the models and variable ranges. Climatic niche models of all the transPalearctic Orthocephalus species are also very similar to two species having more restricted distribution ( $O$. coriaceus, $O$. funestus). Results of this study suggest that transPalearctic distributions can have different geographic ranges and be shaped by different climatic factors. 
1 Climatic niche comparison between closely related trans-Palearctic species of the genus

2 Orthocephalus (Insecta: Heteroptera: Miridae: Orthotylinae)

3

4

5

6

7

8

\section{9}

10

11

12

\section{Anna A. Namyatova ${ }^{1,2}$}

${ }^{1}$ Laboratory of Phytosanitary Diagnostics and Forecasts, All-Russian Institute of Plant Protection, Pushkin-Saint Petersburg, Russia

${ }^{2}$ Laboratory of Insect Taxonomy, Zoological Institute, Russian Academy of Sciences, Saint Petersburg, Russia

Corresponding Author:

Anna A. Namyatova

Universitetskaya emb. 1, Saint Petersburg, 199034, Russia

Email address: anna.namyatova@zin.ru

\section{Abstract}

Previously climatic niche modelling had been studied for only a few trans-Palearctic species. It is unclear whether and to what extent those niches are different and which climatic variables influence such a wide distribution. Here, environmental niche modelling is performed based on the Worldclim variables using Maxent for eight species of the genus Orthocephalus (Insecta: Heteroptera: Miridae: Orthotylinae). This group belongs to one of the largest insect families and it is distributed across Palearctic. Orthocephalus bivittatus, O. brevis, O. saltator and $O$. vittipennis are distributed across Europe and Asia; O. coriaceus, O. fulvipes, O. funesuts, $O$. proserpinae have more limited distribution. Niche comparison using ENMTools was also undertaken to compare the niches of these species, and to test whether the niches of closely related species with trans-Palearctic distributions are more similar to each other, than to other congeners. It has been found that climatic niche models of all trans-Palearctic species under study are similar but are not identical to each other. This has been supported by niche geographic projections, climatic variables contributing to the models and variable ranges. Climatic niche models of all the trans-Palearctic Orthocephalus species are also very similar to two species having more restricted distribution (O. coriaceus, O. funestus). Results of this study suggest that trans-Palearctic distributions can have different geographic ranges and be shaped by different climatic factors.

\section{Introduction}

Environmental niches are important characteristics of species. Studying them can help to identify the environmental factors responsible for maximizing the species' fitness, and lead to a better understanding of how environment is connected to speciation and how closely related species are different in their ecological preferences. Studying climatic niches of 
39

40

41

42

43

44

45

46

47

48

49

50

51

52

53

54

55

56

57

58

59

60

61

62

63

64

65

66

67

68

69

widespread species also can help to reveal the climatic variables, connected with the species ability to adapt to different conditions.

The Palearctic spans thousands of kilometers across different biomes and climatic zones. Species occupying large areas of Europe and Asia in this zoogeographic region are called "trans-Palearctic" and are often treated as having the same type of distribution (e.g. Abe et al. 2007, Hubenov 2008, Potikha 2015). However, the diversity of such distributions and corresponding climatic niches has never been quantitatively studied.

Most investigations of environmental niche differences treated allopatric vertebrate species (e.g. Losos et al., 2003; Graham et al., 2004; Kozak \& Weins, 2006, 2010; McCormack et al., 2010; Blair et al., 2013). There are only a few studies of ecological niche similarities of sympatric species (e.g. Knouft et al., 2006; Wellenreuther et al., 2012; Lison \& Calvo, 2013; Mumladze, 2014; López-Alvarez et al., 2015; Dellacour et al., 2016), and even fewer on insects (Wellenreuther et al., 2012; Dellacour et al., 2016). Many studies show that closely related sympatric species are different in their ecological niches (Wellenreuther et al., 2012; Mumladze, 2014; Aguirre-Gutierrez, 2015; López-Alvarez et al., 2015; Dellacour et al., 2017). However, only a few such works treat Palearctic insects (e.g. Wellenreuther et al., 2012; Dellacour et al., 2016; Avtaeva et al., 2019), and such works on the trans-Palearctic insects are very rare (e.g. Avataeva et al., 2019). Knowledge on climatic niches is also a prerequisite for studying the influence of climate on speciation, i.e. testing niche conservatism vs niche diversification hypotheses (e.g. Losos et al. 2003; Kozak \& Weins, 2006). Therefore, it is essential to study climatic niches of the species widespread in Palearctic to understand the factors connected with such a wide distribution and how those factors relate to the phylogenetic history.

This current project describes the climatic niches and reveals their differences for closely related species of the Palearctic genus Orthocephalus Fieber, 1858 (Insecta: Heteroptera: Miridae: Orthotylinae). These species inhabit meadows and dry open areas, utilizing numerous species of Asteraceae, where at least the widely distributed taxa are likely to be polyphagous. Orthocephalus has been revised (Namyatova \& Konstantinov, 2009), and a morphology-based phylogeny supported its monophyly. Currently Orthocephalus includes 23 species, with O. bivittatus Fieber, 1864, O. brevis (Panzer, 1798), O. saltator (Hahn, 1835), and O. vittipennis (Herrich-Shaeffer, 1835) widely distributed in Europe and Asia 
70 (Namyatova \& Konstantinov 2009). This allows us to test whether the closely related species 71 with wide distribution in the Palearctic occupy the same climatic niche, or whether their 72 niches are significantly different.

Most of the Orthocephalus species have a low number $(<15)$ of records, except for

74

75

76

77

78

79

80

81

82

83

84

85

86

87

88

89

90

91

92

93

94

95

96

97

98

99

100

101 O. coriaceus (Fabricius, 1777), O. fulvipes Reuter, 1904, O. funestus Jakovlev, 1881, and $O$. proserpinae (Mulsant \& Rey, 1852). The records of these species have also been used to build the climatic niches to find the factors influencing their distribution and compare them to those of the widely distributed species. Those niches will also allow testing whether the climatic niches of the species with trans-Palearctic distribution are more similar with each other than with those of the species having limited distribution. Comparisons of climatic niches of the Orthocephalus species will be the first step in answering the question, whether the niche conservatism or niche divergence or both can relate to speciation in this genus.

The aims of the current work are to: (1) compare the niches of widely distributed species with each other and with those of species with limited distribution to determine the main climatic variables responsible for the trans-Palearctic distribution and limited distribution; (2) to test whether the trans-Palearctic species are significantly similar and whether they are more similar to each other or to the species with a limited distribution; and (3) to draw conclusions on the presence of the niche conservatism or niche divergence processes in speciation within Orthocephalus, based on the phylogeny, provided in Namyatova and Konstantinov (2009).

\section{Materials \& Methods}

Specimens and localities sources. Eight species (and number of unique records) have been analyzed in this work Orthocephalus bivittatus (171), O. brevis (146), O. coriaceus (39), O. fulvipes (18), O. funestus (90), O. proserpinae (19), O. saltator (237), and O. vittipennis (208).

Orthocephalus vittipennis is recorded from Western Europe to eastern Yakutia, including numerous records from Central Asia. The distributions of $O$. saltator and $O$. brevis are similar to that of $O$. vittipennis, but among Central Asian countries, they are known only from Kazakhstan. Orthocephalus bivittatus is not recoded from the northern Europe and eastern Siberia, however, is common in Central Asia (Kerzhner \& Josifov, 1999; Namyatova \& Konstantinov, 2009). Orthocephalus coriaceus is mostly known from the middle and northern Europe with few specimens recorded from Kyrgyzstan. Orthocephalus funestus is known only from Northeast Asia. 
102 Orthocephalus proserpinae and O. fulvipes inhabit the Mediterranean region, O. fulvipes is 103 additionally known from Arabian Peninsula and Iran (Kerzhner \& Josifov, 1999; Namyatova \& 104 Konstantinov, 2009). Numerous collecting expeditions have been taken in Central Asia, Mongolia, 105 Siberia, Russian Far East, European part of Russia by the Russian and Soviet entomologists, and 106 their collections are mainly preserved at the Zoological Institute of the Russian Academy of 107 Sciences (Konstantinov \& Namyatova, 2019). Although many records from European countries 108 were excluded (see Methods), this region is still well represented in the current analysis. Therefore, 109 it is likely, that the known distribution for Orthocephalus species probably reflects the real 110 distribution.

111 Specimens used for this study are mostly preserved at the Zoological Institution of the 112 Russian Academy of Sciences, St Petersburg, Russia. This collection holds one of the largest 113 Palearctic collections of Heteroptera. The most label data for the Orthocephalus specimens are 114 recorded in the Arthropod Easy Capture database (https://research.amnh.org/pbi/locality/). Some 115 specimens are preserved at the Canadian National Collection of Insects, Agriculture and Agri116 Food Canada, Ottawa, Canada (CNC), Linnavuori Collection (LCRT), Matocq collection 117 (MATOCQ), Bavarian State Museum in Zoology, Munich, Germany (ZSM), National Museum of 118 Natural History, Paris, France (NMNH), Ribes Collection (JR), American Museum of Natural 119 History, New York, USA (AMNH), Natural History Museum, Geneva, Switzerland (MHNG), 120 Zoological Museum Amsterdam, Netherlands (ZMAN), Carapezza collection (AC), Finnish Museum of Natural History, Helsinki, Finland (MZH), Institute for Biological Problems of 122 Cryolithozone, Yakutsk, Russia (YIB).The specimens have been identified based on the revision 123 of the genus Orthocephalus (Namyatova \& Konstantinov, 2009). This revision corrected species identification errors of previous keys (e.g. Kerzhner \& Jachewski, 1964; Wagner \& Weber, 1965; Wagner, 1974) which were based on variable coloration and not male genitalia structure which proved crucial for accurate determination of the species. To decrease number of erroneous records, in most cases the localities from other papers have been added only if they cited the abovementioned revision (Kment \& Baňař, 2012; Matocq et al., 2014; Heckmann, 2015; Sofronova, 2017; Vinokurov et al., 2017). All records from the literature have been added for O. brevis and O. funestus (Ribes, 1989; Melber et al., 1991; Dioli, 1993; Gorczyca \& Chłond, 2005; Arnold, 2008; Lim et al., 2011, 2012, 2013a, 2013b; Nikolaeva, 2011; Frieß, 2006, 2014; Roháčová, 2007; 
133 2016; Vinokurov, 2016; Gierlański, 2017; Jung et al., 2017; Kozminykh \& Naumkin, 2017), as $O$. 134 brevis can be easily separated from congeners by its widened antennal segment II and O. funestus 135 inhabits Northeast Asia, and this is the only Orthocephalus species known from Northeast Asia 136 (Namyatova \& Konstantinov, 2009). The maps with all records used in this study are provided on 137 Figs 1 and 2 and the list of those records for all species and specimen information are provided in 138 the Supplemental Data 1.

139 Maps. Layers in 5-arc minute $(\sim 10 \mathrm{~km})$ resolution representing different bioclimatic variables have 140 been downloaded from Worldclim, Version 1.4 (https://www.worldclim.org/version1). In general, 141 the finer resolution leads to more accurate predictions, as the data are averaged within the grid cell. 142 For this study coarser resolution was chosen for two reasons. First, it is a trade-off between the 143 high resolution data across large geographic space and computational efficiency, as there is only a 144 little difference between the models built using different scales especially in broadly distributed 145 species (e.g. Araújo et al., 2005; Seo et al., 2008). Seo et al. (2008) also has shown that with a 146 spatial grid size below $16 \times 16 \mathrm{~km}$, there is a good agreement among model area estimated for 147 species of all range sizes. Second, the coordinates for many localities are approximate, and high 148 resolution might also lead to the erroneous interpretations (Graham et al. 2005; Hanberry et al.

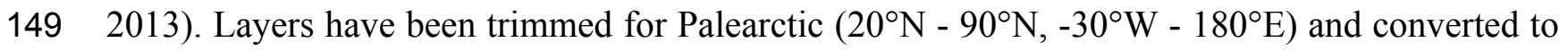
150 ASCII format in DIVA-GIS (https://www.diva-gis.org/). Those layers have been uploaded to 151 QGIS 3.10 and converted to vector and used to create "samples with data" files (swd files).

152 Environmental niche modelling. Maxent software (version 3.4.1) 153 (https://biodiversityinformatics.amnh.org/open_source/maxent/) (Phillips et al., 2006) was chosen 154 because it performs well in comparisons with other programs especially for rare species. It works 155 with presence-only data and is considered to produce robust results with sparse, irregularly 156 sampled data and minor location errors, which is applicable to museum data (Elith et al, 2006, 157 2011; Pearson et al, 2007; Kramer-Schadt et al., 2007). The models have been built using swd files 158 and bioclim layers in ASCII format. For the datasets with $>50$ localities, bootstrap replicated run 159 type with $25 \%$ of localities assigned for the random test percentage were applied. Overall, ten 160 replicates were conducted. For the datasets with $<50$ localities (O. coriaceus, O. fulvipes and O. 161 proserpinae), crossvalidation with the replicate number corresponding to the locality number was 162 used (Pearson at al., 2007; Shcheglovitova \& Anderson, 2013). 
The data used in this study are biased towards the easily accessed area, as most of the

164

165

166

167

168

169

170

171

172

173

174

175

176

177

178

179

180

181

182

183

184

185

186

187

188

189

190

191

192 specimens were collected along major roads and railroads in the area currently corresponding to Russia, as well as Caucasus and Central Asia countries. This can exacerbate over-representation

of some regions, which can lead to an inaccurate model. Sampling bias can be addressed by reducing the number of occurrence records in oversampled regions using spatial filtering (Dormann et al., 2007; Kramer-Schadt et al., 2013); however, it can lead to a situation where the number of occurrences is too few to create a reliable model. Additionally, Maxent automatically discards the redundant records, appearing in the single grid cell (Fourcade et al. 2014, Chiarenza et al. 2019), which is $\sim 10 \mathrm{~km}$ in this study. This is a quite large area, which might accommodate different climate regimes. Assigning the larger grid cell was needed for the filtering, and leading to further loss of information on species climatic preferences. Alternatively, it is possible to manipulate the background data by choosing background data with the same bias as occurrences (Phillips et al., 2009; Elith et al., 2011; Kramer-Schadt et al., 2013). As soon as there are $<20$ occurrences for two of the analyzed species, the bias file approach was chosen. A previous study showed that using biased background data have increased the performance of the model and should be applicable for cases with small numbers of occurrence points (Kramer-Schadt et al., 2013). A bias file was created as a two-dimensional kernel density estimate, based on the coordinates of the occurrence points, using the kde2d function from the MASS package (Ripley et al., 2020) in R. This approach was applied in previous works (e.g. Filazzola et al., 2018; Mudereri et al., 2020). Bias files were converted to the raster ASCII format and have been implemented into the biasfile option in Maxent. Ten thousand background points, which is the default Maxent setting, was randomly selected from the area denoted in the bias file. The "cloglog" output was chosen for the visualization and further analysis.

Variable selection. Climatic niche modelling with two sets of variables was conducted. To avoid the model overfitting, it is possible to exclude the highly correlated variables and/or tune the model parameters (Merrow et al., 2013). It has been shown that Maxent can perform well with the correlating variables with tuned parameters (Merrow et al., 2013; Morales et al., 2017; De Marco Junior \& Nobrega, 2019); therefore, the first model type includes all bioclimatic variables (CF model). However, to test whether the model with all variables can be overfitted the highly correlated variables for each species were excluded (CR model) (see below for the details).

Peer) reviewing PDF | (2020:04:48200:2:1:NEW 14 Nov 2020) 
193 Parameter adjustment. There are two modifiable parameters in Maxent, which are feature classes 194 and regularization multiplier. They should be adjusted for each particular case to avoid overfitting 195 and/or over-complexity (Morales et al., 2017). Feature classes correspond to the mathematical

196

197

198

199

200

201

202

203

204

205

206

207

208

209

210

211

212

213

214

215

216

217

218

219

220

221

222

223 transformation of the variables and regularization multiplier (beta multiplier) limits the complexity of the model and generates a less localized prediction; i.e. smooths the model (Phillips \& Dudík, 2008; Elith et al. 2011, Merrow et al., 2013). Best features and regularization multiplier set for the CF models has been selected using ENMeval package in R (Muscarella et al., 2014a, 2014b), using Maxent. The models have been tested against the regularization multipliers ranged from 0.5 to 6 and the default feature classes and their combinations, i.e. L, LQ, LQH, H, LQHP, LQHPT (L = linear, $\mathrm{Q}=$ quadratic, $\mathrm{H}=$ hinge, $\mathrm{P}=$ parameter, $\mathrm{T}=$ threshold). The method "block" was chosen, because it accounts for spatial autocorrelation (Muscarella et al., 2014a). This analysis can result in different parameter sets in different runs, so the analysis was done five times for each species. In case if the analyses resulted in different parameter sets, all of them were kept to run the environmental niche modelling in Maxent. All the parameter sets used for the modelling are provided in the Supplemental Table 1.

For the CR model, the MaxentVariableSelection package in R (Jueterbock et al., 2016; Jueterbock, 2018) was used. It chooses the best set of variables, which has the lowest AICc value, based on the regularization multiplier and features. Comparisons were performed for the same parameters, as in the case of the ENMeval. A separate run was conducted to test the regularization multipliers for each feature class or combinations of classes. For the background data ten thousand background points were extracted from the bias file raster using R. For each feature (or combination of the features), its best regularization multiplier and variable set was kept for further analysis in Maxent, and they are provided in the Supplemental Table 1.

Maxent provides the list of the percent contribution (PC) and permutation importance (PI) for each variable in the model. The variables with PC and/or PI values higher than $10 \%$ are provided in Table 1 for CF and CR models for each species.

Model evaluation. For model evaluation, training and test AUC values are provided, which is valid for model comparison over the same study area (Bohl et al., 2019) (see Supplemental Table 1). The differences between training and test AUC values and omission error rates have been also compared. It has been shown that the model with high differences between AUC values and 
224 omission error rate $>0.1$ is likely to be overfitted (Bohl et al., 2019). In the case of each model 225 type ( $\mathrm{CF}$ and $\mathrm{CR}$ ), the model with the relatively high AUC values, low differences between 226 training and test AUC and low omission error rates was chosen for the visualization and niche 227 comparisons.

228 Environmental niche projection area and climatic variable ranges. The obtained environmental 229 niche models were thresholded using the "Maximum training sensitivity plus specificity Cloglog 230 threshold", as the thresholds maximizing sensitivity and specificity perform well on presence only 231 datasets (Liu et al., 2016). The total area of the thresholded niche projection was obtained using 232 QGis 3.10. The thresholded maps were used as masks to trim the bioclim layers to obtain the 233 climatic variables ranges for each model. These areas and variable ranges were used to compare 234 the models. The correlation of climatic variables was estimated for each species separately using 235 Pearson's correlations (PCor), as it is suitable for continuous variables. In this work PCor $\geq 0.9$ is 236 considered strong, as it is usually used to discriminate strongly correlated variables (e.g. Jezkova 237 et al., 2011; Dellicour et al., 2014). I also considered $0.7 \leq$ PCor $>0.9$ as significant. Tables with 238 Pearson's correlations for the each species are provided in the Supplemental Data 2.

239 Niche overlap. Testing for niche overlap was performed in ENMTools (Warren et al., 2010). First, 240 the niche overlap was conducted to get the Schoener's D (D) and Hellinger distance I (I) metrics, 241 these measure similarities between species habitat suitability models. The values of both metrics 242 ranged from 0 (the niches do not overlap) to 1 (the niches are identical). Comparisons were run 243 between all species within each model type, CF and CR, separately. Second, the "Identity test" for 244 each pair of species was conducted. This test randomizes the occurrences for two species, creating 245 the pseudopopulations, and compares the environmental niches for those datasets, creating 246 permuted D and I values. If the D and I values for the actual data are significantly lower than those 247 of the randomized (permuted) data the niches are interpreted to be different (Warren et al., 2010).

248 The identity test can be performed only for the same set of environmental layers for both compared 249 species; therefore, the identity test was used for the models with all environmental variables. Third, 250 the background test was also performed. It measures the difference between the similarity of two 251 species on one side and the similarity between species and background of another species on the 252 other side. The test should be undertaken for two sides, as it can yield different results for the 253 reversed comparison. If the D and I metrics for actual niche overlap and obtained with background 254 test are similar, this means that the similarity of niches between two species is the same as expected 
255 from random data. If the D and I metrics of actual datasets are higher or lower than those from 256 background test, this means that the niches are more similar or more different than expected from 257 random data respectively (Warren et al., 2010). The background for each species equals to its bias 258 file.

259 Maps visualization. All maps have been prepared in QGis 10. The background for the Figs 1-2 is 260 the layer freely accessible at https://github.com/nvkelso/natural-earth-quick261 start/tree/master/50m_raster/NE1 50M_SR_W, and it is not copyrighted. The maps for Figs 3-6 262 have been created by the uploading the averaged maps resulted from the Maxent analysis to QGis 263 10. The country borders layer is freely accessible at 264 https:/github.com/petewarden/openheatmap/tree/master/mapfileprocess/test_data/TM_WORLD 265 _BORDERS-0.3, and it is not copyrighted.

266

267 Results

268 Model evaluation. All the Maxent models have high discriminative power for the training datasets 269 with high AUC. It is higher than 0.9 in all cases except for $O$. vittipennis, where AUC ranges from 2700.87 to 0.89 . The models are also able to predict the testing points with very similar AUC values, 271 as in training datasets. The training AUC is higher than the test AUC, and the differences between 272 the models chosen for the comparison vary from 0.002 (CF model for O. bivittatus) to 0.027 (CR 273 model for O. vittipennis). Omission rates for the models chosen for the comparisons vary from 2740.0789 (CR model for O. funestus) to 0.1620 (CF model for O. vittipennis). The AUC values and 275 omission rates for all models are provided in the Supplemental Table 1. The Maxent output files 276 for each model chosen for the visualization and niche comparison are provided in the Supplemental 277 Data 3. The detailed descriptions of the climatic niches for each species are provided in the 278 Supplemental Data 4.

279 The model with all variables is supposed to be overfitted because of the correlated 280 variables. Therefore, this model is expected to predict smaller areas of suitable conditions and/or 281 narrow ranges of the climatic variables, than the model with reduced set of variables (see 282 Methods). However, the current results do not support this idea. The thresholded maps of the 283 modelled areas with suitable conditions are provided in Figs 3-6. Those areas of CF models are 284 larger than or subequal to CR for all the species. In the case of variables ranges no model type is 285 noticeably more restrictive than the other (Figs 7-11). In rare cases, the CF models show 
286 significantly more restricted ranges, rather than CR models (e.g. bio12, bio13 for O. bivittatus and 287 O. proserpinae, bio18 for $O$. proserpinae). The variables ranges for each model are shown on the 288 Figs 7-11.

The climatic variables with high PC and PI for each model type and for each species are

290

291

292

293

294

295

296

297

298

299

300

301

302

303

304

305

306

307

308

309

310

311

312

313

314

315

316

provided in the Table 2. Both models for the same species have different sets of climatic variables explaining their distribution, and each type of model (CF or CR) has different sets of climatic variables explaining the distribution in comparison between the species.

In most of the models both temperature related and precipitation related variables, are important for the species distribution, except for the CF models for O. saltator and O. vittipennis, having only temperature related variables significantly contributing. Most of the variables appear as important for at least one model, except for bio5 (max temperature of warmest month), bio8 (mean temperature of wettest quarter), bio12 (annual precipitation) and bio13 (precipitation of wettest month). In some cases, the same variable significantly contributes to the both type of models within the same species, i.e. biol (annual mean temperature for O. bivittatus and O. brevis, bio3 (isothermality) for $O$. coriaceus and $O$. funestus, bio4 (temperature seasonality) for $O$. proserpinae, bio14 (precipitation of driest month) for O. brevis, bio18 (precipitation of warmest quarter) for $O$. fulvipes, bio19 (precipitation of coldest quarter) for $O$. coriaceus and $O$. proserpinae.

\section{Comparison of the variables for the species with similar environmental niches}

Annual mean temperature (bio1) is important for all widely distributed species. In the case of the CR models for $O$. saltator and $O$. vittipennis this variable does not explain the distribution much. However, min temperature of coldest month (bio6) is important for this type of model in $O$. saltator, and mean temperature of driest quarter (bio9) is important for the CR model in $O$. vittipennis, and bio6 and bio9 significantly correlate with each other and biol (PCor $>0.87$ ) in those two species (Table 2). Temperature annual range (bio7) and mean temperature of coldest quarter (bio11) highly contribute to at least one of the models in O. bivittatus, O. saltator and $O$. vittipennis, and they also significantly correlate with each other in all those species, as well as with bio1, bio6 and bio9 for most of the species. In the models of two species, widely occurring in Central Asia (O. bivittatus and O. vittipennis), mean diurnal range (bio2), bio9, precipitation of driest quarter (bio11) and precipitation of warmest quarter (bio18) significantly contribute to at least one of the models. In O. bivittatus and O. brevis precipitation seasonality (bio15) is important 
317 for at least one of the models. In $O$. brevis precipitation of driest month (bio14) significantly 318 contributes to both models. Max temperature of warmest month (bio5), mean temperature of 319 wettest quarter (bio8), annual precipitation (bio12), precipitation of wettest month (bio13), 320 precipitation of driest quarter (bio17) only slightly contribute or do not contribute to the climatic 321 models of the trans-Palearctic species.

322 Suitable conditions for $O$. bivittatus are shifted to drier places than in other species, 323 whereas suitable conditions for $O$. brevis are predicted for the places with higher precipitation than 324 in other species. In contrast to other species, suitable conditions for $O$. vittipennis are predicted in 325 areas with very low temperatures over the winter and very strong seasonality. The models for $O$. 326 saltator are similar to $O$. brevis in precipitation levels and temperature changes around the year; 327 however, suitable conditions of the former are also predicted for the areas with warmer 328 temperatures over the summer, than in $O$. brevis.

The models of $O$. coriaceus are more similar than random with all the models of widespread species (Table 1). It is different from all of them in the lower margins for isothermality (bio3) limited with higher values (Fig. 7), and suitable conditions are predicted for the places with low temperatures over summer (bio5, bio10) (Figs 8, 9). The models for $O$. bivittatus and $O$. vittipennis are additionally different from those of $O$. coriaceus in variables described in the model descriptions for those species (see Supplemental data 4). The models of O. coriaceus are most similar to those of $O$. brevis and $O$. saltator, which also occupy almost all Europe. Precipitation of driest month (bio14) significantly contributes to both models for O. brevis and O. coriaceus (Table 2). However, in contrast to $O$. brevis, suitable conditions for $O$. coriaceus are modelled for the places with very low values for this variable, as well as for precipitation of the driest quarter (bio17) (Fig. 10,11). The models of $O$. coriaceus differ from $O$. saltator in the upper margin of the precipitation of the driest month and quarter (bio14, bio17) range limited with higher values 341 (Figs 10, 11), and the upper margin of seasonality (bio4) limited with lower values (Fig. 7). The models for the northeastern $O$. funestus are more similar than random with $O$. brevis, $O$. saltator and $O$. vittipennis, and they are most similar to $O$. brevis and $O$. vittipennis. The models 344 of $O$. funestus are different from those of abovementioned three widespread species in isothermality (bio3) range very narrow and shifted towards lower values (Fig. 7). In contrast to all other species, suitable conditions for $O$. funestus and $O$. vittipennis are modelled for the places 
348 strong seasonality (bio4) (Figs 7-9). The upper margins of the diurnal range (bio2), isothermality 349 (bio3), temperature seasonality (bio4), temperature annual range (bio7) are limited with the lower 350 values (Figs 7-8), and the upper margins are limited with higher values for many precipitation

351

352

353

354

355

356

357

358

359

360

361

362

363

364

365

366

367

368

369

370

371

372

373

374

375

376

377

378 variables (bio12-14, 16, 17-19) in O. funestus in comparison with $O$. vittipennis (Figs 9-11).

Both, $O$. funestus and $O$. brevis have suitable conditions in places with high precipitation over the different seasons (bio12, bio14, bio17) (Figs 9-11), but ranges of many temperature related variables (bio1, bio5, bio6, bio9, bio11) and seasonality (bio4) are limited with the lower margins in O. funestus than in O. brevis (Figs 7-9). Orthocephalus funestus differs from O. saltator in the variable ranges modelled for the places with stronger annual temperature changes (bio4, bio7), lower temperatures over the different seasons (bio5, bio6, bio9, bio11) and higher precipitation (bio12-14, 16-19) (Figs 7-11).

Both O. fulvipes and O. proserpinae inhabit southern areas of European Palearctic (Figs 1D, 2B), but the variables contributing to their models are different (Table 2). For both species in the CF model the mean temperature of driest quarter (bio9) is important. Precipitation over wettest or coldest quarters (bio16 and bio19) significantly contribute to the models of both species. They also have either precipitation of driest month (bio14) or precipitation of warmest quarter (bio18) high PC. They have also similar ranges for isothermality (bio3) and temperature seasonality (bio4), as well as higher temperatures of driest and coldest periods (boi6, bio9, bio11), and lower precipitations over the driest and warmest periods (bio14, bio17, bio18) (Figs 7-11). The models of $O$. fulvipes differ from those of $O$. proserpinae in many temperature variables limited with higher values (bio5, bio6-bio11) (Figs 8-9), as well as mean diurnal range and temperature seasonality and precipitation of driest month (bio2, bio4, bio14) (Fig. 7, 10) .

\section{Niche overlap, identity test and background test}

The results for the niche overlap, identity test and background test are shown in the Table 1. The I and D metrics show that the niche overlap between all widely distributed species is relatively high in comparison to cases when widely distributed species is compared with locally distributed species, or locally distributed species are compared with each other (I $>0.8, \mathrm{D}>0.5)$. Similar values are for the overlap between the following pairs: O. brevis and O. coriaceus, O. saltator and O. coriaceus, O. funestus and $O$. vittipennis. The largest niche overlap is between $O$. brevis and $O$. saltator $(\mathrm{I}>0.9, \mathrm{D}>0.6)$, as well as between $O$. brevis and $O$. vittipennis $(\mathrm{I}>0.8, \mathrm{D}>0.6)$. 
379 However, identity test shows that those values do not reach 5\% threshold for permuted I and D

380

381

382

383

384

385

386

387

388

389

390

391

392

393

394

395

396

397

398

399

400

401

402

403

404

405

406

407

408

409

values, which means that we cannot conclude that the niches are identical.

The background test shows that all pairs of the widespread species are more similar to each other than expected for both CF and CR models and for comparisons in both sides, based on I and $\mathrm{D}$ metrics. The same result is shown for the comparisons of $O$. coriaceus with all widespread species, as well as for the following pairs: O. funestus and O. brevis, O. saltator and O. vittipennis, $O$. funestus and $O$. saltator, $O$. funestus and $O$. vittipennis, $O$. coriaceus and $O$. proserpinae, $O$. fulvipes with $O$. proserpinae. Background test undoubtedly shows that the niches are more different from each other only for $O$. funestus vs $O$. proserpinae comparison. In all other cases the results are dubious and differ depending on the type of model and statistical metric. The results also can differ for the pair of species, depending which species is used for the background. Generally, the CR models show more overlap with each other than the CF models, and background test is more often shows that the species are more similar to each other for the CR models. If two widespread species are compared, the background test results in very similar metrics values for both directions. If two species with very different areas of suitable conditions sizes are compared, the results depend on which of them is used for the background. In case when the species with larger distribution area is used as a background, the resulted metrics are lower, and therefore, the analysis shows that two species are more similar to each other than expected more often, rather than in the reversed comparison.

\section{Discussion}

Climatic niches of Orthocephalus species comparison. The modelled environmental niches for the widespread species cover noticeably different areas. Areas in which conditions are suitable for $O$. bivittatus correspond with the other species the least. They are mostly projected on Central Asia and south of European part of Russia. (Figs 3A, 4A). Orthocephalus brevis and $O$. saltator are more similar, having the largest area of suitable conditions in Western Palearctic, however, the geographic projections of their environmental niches do not cover the Mediterranean region for $O$. brevis, whereas those areas are suitable for $O$. saltator (Figs 3B, 4C, 5B, 6C). Suitable conditions for $O$. vittipennis extend through entire Eurasia, from Europe to Northeast Asia, including Central Asia, (Figs 5D, 6D), whereas the Mediterranean area is not suitable for this species. Those differences in the areas of suitable conditions are also supported by the differences 
410 in the variables with highest contribution to the climatic models (Table 1) and comparisons of 411 climatic variable ranges (see Results section for the details). Overall, all analyzed Orthocephalus 412 species have different set of variables, most important for their climatic models and none of the 413 pairs have identical climatic niches, which suggests that the climatic niche is species specific even 414 for the closely related taxa. Finally, the differences in the environmental niches are also supported 415 by the identity tests and comparisons of climatic variable ranges. Although in all widespread 416 species niche overlap is high $(\mathrm{I}>0.8, \mathrm{D}>0.6)$ and background test shows that the similarity between 417 them is higher than that of random data, the identity test does not support the hypothesis that they 418 are identical (Table 1). This supports the previous research, showing that the environmental niches 419 in closely related species might be similar, but not identical (e.g. Wellenreuther et al. 2012, López420 Alvarez et al. 2015, Dellacour et al. 2016).

421 The climatic niche models of Trans-Palearctic species are all more similar to each other 422 than expected. The niches of $O$. coriaceus and $O$. funestus, distributed in Europe and northeast 423 Asia respectively, also highly overlap with some Trans-Palearctic species. The climatic niche 424 models of $O$. fulvipes and $O$. proserpinae, are not very similar with Trans-Palearctic species. Schmitt (2007) made an overview of the European types of distribution, and delimited three main types. Species with the center of dispersal in Mediterranean regions are "Mediterranean", species having extra-Mediterranean center of dispersal belong to "Continental" type, and species with recent alpine of arctic distribution patterns are called "Alpine" or "Arctic". Testing the center of the distribution for the Orthocephalus species is beyond the scope of the current paper: a phylogeography analysis combined with modelling of distribution during the glacial period is necessary for such a study. However, it is very likely that the trans-Palearctic Orthocephalus species belong at least to two Schmitt's groupings (2007). Among the analyzed widespread species, suitable conditions in the Mediterranean region are generally not predicted for $O$. bivittatus, O. brevis and $O$. vittipennis and they probably belong to the "Continental" group. However, $O$. saltator has highly suitable climatic conditions in the Mediterranean region and might have its center of dispersal there (Figs 5C, 6C).

Maps with the records and the areas of suitable conditions suggests that "trans-Palearctic" distribution is a term of convenience and might include many types of distributions connected with the different climatic conditions. Study of more species from different taxonomic groups, 
441 of environmental niches are suitable for the trans-Palearctic species and which climatic conditions 442 are connected with such distributions.

$443 \quad$ Climatic variables important for the Orthocephalus distribution

444 Annual mean temperature (bio1), temperature annual range (bio7) and mean temperature of coldest 445 quarter (bio11) are important for the models of at least three widely distributed Orthocephalus 446 species. The results also correspond with the results of environment niche modelling of the trans447 Palearctic beetle species Pterostichus oblongopunctatus (Fabricius, 1787), which showed that bio1 448 and bio11 had high contribution to the model of this species (Avtaeva et al. 2019). Modelling of 449 the trans-Palearctic tick Ixodes ricinus (Linnaeus, 1758) showed that min temperature of coldest 450 month (bio6) is among the variables with the highest PC in the climatic model of this species 451 (Porretta et al. 2013) In all trans-Palearctic species bio6 and bio11 highly correlate with bio1 (PCor $452>0.9$ ), and this might mean that the distribution of the trans-Palearctic arthropods is limited at least 453 partly by the winter temperatures. Overall, the set of the variables having high contribution to the 454 climate models is unique for each Orthocephalus species, and analysis of more trans-Palearctic 455 species is needed to make conclusions hon ow type of distribution correlates with the climatic 456 variables.

457 Orthocephalus brevis, O. coriaceus, P. obongopunctatus and I. ricinus are mostly distributed in 458 the Western Palearctic, and their climatic models have precipitation of driest month (bio14) or 459 460 precipitation of driest quarter (bio17) with high PC. This reflects the fact that the most suitable conditions for all those species cover middle and northern Europe, but not Mediterranean zones, and therefore prefer the places with relatively high precipitation around the year. This is also 462 463 supported by the variable ranges of bio14 and bio17 variables for $O$. brevis and $O$. coriaceus, which show that these species inhabit places with high precipitation values over the driest period. Similarly to four mentioned species, Orthocephalus saltator is mostly distributed in Western 466 Palearctic, but the areas with the most suitable conditions cover Mediterranean zones. In case of this species, bio14 and bio17 do not contribute much to the climatic model $(<10 \%$ of PC and PI). Although $O$. coriaceus and $O$. funestus have very different distribution, isothermality (bio3) has high PC and PI for both models in both species. However, according to the temperature ranges the former tends to inhabit places with high isothermality, whereas the latter prefers the areas with low values of this variable. The study with more European and East Asian species is needed to confirm that isothermality is connected with such distributions. 
472 The precipitation related variables over the different seasons (bio14, bio15, bio18, bio19) are 473 important for models for two species mostly distributed in the Mediterranean regions, and mean 474 temperature of driest quarter (bio9) has high PC and PI in the CF model. This is similar to the 475 Mediterranean species of Tomicus destruens (Wollaston, 1865) (Sánchez-García et al., 2013). It 476 was shown that the variables bio19 and bio9 are also important for the climatic models of different 477 clades and haplotypes of this species. Study of climatic preferences of more insect species from 478 the Mediterranean region is needed to draw conclusions on how the climate is connected with the 479 species distribution in this region.

480

481 482

483

Comparison of environmental niches between closely related Orthocephalus species in the phylogenetic context

484

Although, a morphology-based phylogeny for Orthocephalus has been published (Namyatova \& Konstantinov 2009), there are many unresolved clades, and, therefore, cannot be 485 used to adequately analyze potential phylogenetic signal in climatic related tolerances and environmental niches. However, a few conclusions still can be reached. According to this phylogeny, O. bivittatus, O. coriaceus, O. fulvipes, O. funestus, O. saltator and O. vittipennis have 488 very similar vestiture, color and genitalia, and in some cases the species can be identified only from the males. Those species form a clade, which also includes some other species. Orthocephalus brevis and O. proserpinae are very different morphologically, and are not closely 491 related to other species.

Based on these relationships, it can hypothesized that there are at least three processes in 494 this genus related to climatic niches which might be at play. First, there might be phylogenetic conservatism, at least for some climatic variables. For example, O. funestus and O. vittipennis are very similar morphologically. They mostly differ only in hemelytron coloration in males. According to the current analysis, their niches are also more similar to each other than to random data, and both those species can tolerate strong seasonality and very low winter temperatures. Another example is O. fulvipes, inhabiting southwestern Palearctic, which morphologically is very 499 similar to $O$. saltator, and the latter is the only widespread species in which the Mediterranean 500 region is suitable. 
501

502

503

504

505

506

507

508

509

510

511

512

513

514

515

516

517

518

519

520

521

522

523

524

525

526

527

528

529

530

531

Second, climatic niche convergence is also observed. This study found that climatic niches are very similar in $O$. brevis and $O$. saltator, as well as $O$. brevis and $O$. vittipennis, and those pairs are not closely related.

Third, the analysis shows the possibility of the distinct niche divergence in the distantly related taxa. According to the background test, the niches are undoubtedly more different from each other than from random data only for the $O$. funestus and $O$. proserpinae pair. According to Namyatova and Konstantinov (2010), those two species are not closely related. Those significant niche differences might be explained by differences in habitats, occupied by those two species. Orthocephalus funestus inhabits places in northeast Asia with wide ranges of temperatures and high precipitations, whereas $O$. proserpinae lives in the Mediterranean region with narrow temperature ranges and low precipitation (Figs 5B, D, 6B, D). However, O. fulvipes, which is more closely related to $O$. funestus, also prefers dry conditions including Mediterranean and desert climates (Figs 3D, 4D). The background test for this species pair provides inconsistent results, suggesting that the niches between $O$. funestus and $O$. fulvipes are more similar with each other, than those of $O$. funestus and $O$. prosepinae. This leads to the hypothesis that the closely related species in Orthocephalus cannot diverge very quickly.

However, the robust molecular-based phylogeny and niche models for other Orthocephalus species are needed to test all those hypotheses on the niche evolution in this genus.

Based on this phylogeny, it is unclear whether the ability for the wide distribution has phylogenetic signal. On one hand, it is very likely that two closely related species can similarly adapt to the climatic conditions (e.g. Losos 2008, Wiens et al. 2010). On the other hand, even though both sister species can potentially tolerate wide range of climatic conditions, one species might have significantly limited realized niche and distribution because of the strong competition with its sister species.

\section{Conclusions}

The study on the climatic niche modelling for eight insect species with trans-Palearctic distribution from the genus Orthocephalus has been performed. The niches of widely distributed transPalearctic species (O. bivittatus, O. brevis, O. saltator, O. vittipennis) are very similar to each other, but not identical. The differences are confirmed by the "Identity test" and "Background test" in ENMTools, as well as the comparison of the climatic variables contributing to the modes and 
532 variable ranges for the areas, covered by preferable conditions of different species. The niches of

533 the trans-Palearctic species are also similar to two species having more limited distribution $(O$.

534 coriaceus, O. funestus). Overall, the similarity of the niches of widely distributed species is higher

535 than in cases when the niches of widely distributed and locally distributed species or only locally

536 distributed species are compared. The annual mean temperature significantly contributes (bio1) to

537 the climatic models of all trans-Palearctic species. Other temperature related variables, i.e. min

538 temperature of coldest month (bio6), temperature annual range (bio7), mean temperature of driest

539 quarter (bio9), mean temperature of coldest quarter (bio11) are likely to be important for the

540 climatic niches of the trans-Palearctic species. For the trans-Palearctic species, widely distributed

541 on Central Asia, mean diurnal range (bio2), min temperature of coldest quarter (bio11) and

542 precipitation of warmest quarter (bio18) are also important for at least one of the models. For the

543 Western Palearctic species with the most suitable conditions corresponding to the areas outside the

544 Mediterranean regions (O. brevis and O. coriaceus), precipitation of driest month (bio14) is

545 important. Isothermality (bio3) has high PC and PI for European O. coriaceus and East Asian $O$.

546 funestus. For the species, distributed in Mediterranean region (O. fulvipes and O. proserpinae),

547 precipitation related variables over different seasons (bio14, bio16, bio18, bio19), significantly

548 contribute to at least one of the model each. The discussion of the results based on the phylogeny

549 suggests that within Orthocephalus there might be different processes connected to the climate

550 niche differentiation, such as niche conservatism, niche convergence and niche divergence. More

551 studies of climatic niches of the species distributed in the Palearctic are needed to better understand

552 the types of possible climatic niches of widespread species, the main climatic variables shaping

553 the distribution of the Palearctic taxa and how the climatic niches are related to phylogenetic

554 history.

555

\section{Acknowledgements}

557 I am grateful to the curator of the Heteroptera collection (Zoological Institution of the Russian

558 Academy of Science), Fedor Konstantinov and the Head of the Laboratory of Insect Taxonomy

559 (Zoological Institution of the Russian Academy of Science), Sergey Sinev, for the access to the

560 collection. I thank Liudmila Osipova (International Council of Clean Transportation, Berlin,

561 Germany) for the assistance with the niche modelling methodology and Elena Pazhenkova (St

562 Petersburg State University, St Petersburg, Russia) for consultations on graphs visualizations

563 with R. I'm grateful to Michael Schwartz (Agriculture \& Agri-Food Canada, Canadian National

564 Collection of Insects, Ottawa, Canada), Michael Elias (New South Wales Department of Primary 
565 Industries Biosecurity collections, Orange, Australia) and Igor Danilov (Zoological Institution of 566 the Russian Academy of Science) for helping to revise the manuscript.

567 References

568 Abe Y, Melika G, Stone, GN. 2007. The diversity and phylogeography of cynipid gallwasps

569

570

571

572

573

574

575

576

577

578

579

580

581

582

583

584

585

586

587

588

589

590

591

592

593

594

595

(Hymenoptera: Cynipidae) of the oriental and eastern Palearctic regions, and their associated communities. Oriental insects 41(1):169-212.

Aguierre-Gutiérrez J, Serna-Chavez HM, Villalobos-Arambula AR, Perez de la Rosa JA, Raes N. 2015. Similar but not equivalent: ecological niche comparison across closely-related Maxican white pines. Diversity and distributions 21(3):245-257 https://doi.org/10.1111/ddi.12268.

Araújo MB, Thuiller W, Williams PH, Reginster I. 2005. Downscaling European species atlas distributions to a finer resolution: implications for conservation planning. Global Ecology and Biogeography 14(1):17-30 https://doi.org/10.1111/j.1466-822X.2004.00128.x.

Arnold K. 2008. Aktuelle Heteropteren-Funde nach 1980 aus dem Freistaat Sachsen (Insecta: Hemiptera)-2. Beitrag. Faunistische Abhandlungen (Dresden) 25:79-89.

Ataeva TA, Sukhodolskaya RA, Skripchinsky AV, Brygadyrenko VV. 2019. Range of Pterostichus oblongopunctatus (Coleoptera, Carabidae) in conditions of global climate change. Biosystems Diversity 27(1):76-84 DOI: 10.15421/011912.

Blair ME, Sterling EJ, Dusch M, Raxworthy CJ, Pearson RG. 2013. Ecological divergence and speciation between lemur (Eulemur) sister species in Madagascar. Journal of Evolutionary Biology 26(8): 1790-1801 https://doi.org/10.1111/jeb.12179.

Bohl CL, Kass JM, Anderson RP. 2019. A new null model approach to quantify performance and significance for ecological niche models of species distributions. Journal of Biogeography 46(6):1101-1111 https://doi.org/10.1111/jbi.13573.

Chiarenza AA, Mannion PD, Lunt DJ, Farnsworth A, Jones LA, Kelland SJ, Allison PA. 2019. Ecological niche modelling does not support climatically-driven dinosaur diversity decline before the Cretaceous/Paleogene mass extinction. Nature communications 10(1): $1-14$.

Cho YB, Yoon SJ, Yoon SM, Ryu JW, Min HK, Oh KS. 2008. Insect Fauna of Gyeongju National Park, Korea. Journal of Korean Nature 1(1):11-20 https://doi.org/10.1016/S1976$8648(14) 60122-5$.

Peer) reviewing PDF | (2020:04:48200:2:1:NEW 14 Nov 2020) 
596 Cho YJ, Lee YH, Oh JB, Suh SJ, Choi DS. 2011. Some Notes on the Insect Fauna of Gadeok-do 597 Island. Journal of Korean Nature 4(4):319-324 https://doi.org/10.7229/jkn.2011.4.4.319.

598 De Marco Junior P, Nobrega CC. 2018. Evaluating collinearity effects on species distribution

599 models: An approach based on virtual species simulation. PloS one 13(9): e0202403

600 https://doi.org/10.1371/journal.pone.0202403.

601 Dellicour S, Kastally C, Varela S, Michez D, Rasmont P, Mardulyn P, Lecocq T. 2017.

602 Ecological niche modelling and coalescent simulations to explore the recent geographical

603 range history of five widespread bumblebee species in Europe. Journal of

604 Biogeography 44(1):39-50 https://doi.org/10.1111/jbi.12748.

605 Dioli P. 1993. Eterotteri insubrici ed eterotteri xerotermici nei territori perilacustri della

606 Lonbardia e del Ticino. Ecologia dell'Insubria e del Ticino: atti dell'XI convegno

$607 \quad$ nazionale 11:81-86.

608 Dormann CF, Elith J, Bacher S, Buchmann C, Carl G, Carré G, Garcia Marquez JR, Gruber B,

609 Lafoourcade B, Leitao PJ, Münkemüller T, Mcclean C, Osborne PE, Reineking B,

610 Schröder B, Skidmore AK, Zurell D, Lautenbach S. 2013. Collinearity: a review of

611 methods to deal with it and a simulation study evaluating their

612 performance. Ecography 36(1):27-46 https://doi.org/10.1111/j.1600-0587.2012.07348.x.

613 Elith JH, Graham CP, Anderson R, Dudík M, Ferrier S, Guisan A, Hijmans RJ, Huetmann F,

614 Leathwick JR, Lehmann A, Li J, Lohmann LG, Loiselle BA, Manion G, Moritz C,

615 Nakamura M, Nakazawa Y, Overton JMM, Peterson AT, Phillips SJ, Richardson K,

616 Scachetti-Pereira R, Schapire RE, Soberón J, Williams S, Wisz MS, Zimmermann NE.

617 2006. Novel methods improve prediction of species' distributions from occurrence

618 data. Ecography 29(2):129-151 https://doi.org/10.1111/j.2006.0906-7590.04596.x.

619 Elith J, Phillips SJ, Hastie T, Dudík M, Chee YE, Yates CJ. 2011. A statistical explanation of

620 MaxEnt for ecologists. Diversity and distributions 17(1):43-57

621 https://doi.org/10.1111/j.1472-4642.2010.00725.x.

622 Filazzola A, Sotomayor DA, Lortie CJ. 2018 . Modelling the niche space of desert annuals needs 623 to include positive interactions. Oikos 127(2):264-273 https://doi.org/10.1111/oik.04688.

624 Frieß T. 2006. Naturschutzfachliche Analyse der Wanzenfauna (Insecta, Heteroptera)

625 unterschiedlicher Almflächen im Nationalpark Gesäuse (Österreich, Steiermark). Denisia

$626 \quad 19: 857-873$. 
627 Frieß T. 2014. Die Wanzenfauna (Insecta: Heteroptera) des Nationalparks Gesäuse (Österreich, 628 Steiermark). Beiträge zur Entomofaunistik 15:21-59.

629 Gierlański G. 2017. Nowe dane o występowaniu pluskwiaków różnoskrzydłych (Hemiptera:

630 Heteroptera) na użytkach zielonych w Masywie Śnieżnika (Sudety Wschodnie).

631 Heteroptera Poloniae - Acta Faunistica 11:7-13.

632 Gorczyca J, Chłond D. 2005. Orthotylinae of Poland - faunistic review (Hemiptera, Heteroptera, 633 Miridae). Annals of the Upper Silesian Museum (Entomology) 13:87-134.

634 Graham CH, Ron SR, Santos JC, Schneider CJ, Moritz C. 2004. Integrating phylogenetics and 635 environmental niche models to explore speciation mechanisms in dendrobatid 636 frogs. Evolution 58(8):1781-1793 https://doi.org/10.1111/j.0014-3820.2004.tb00461.x.

637 Heckmann R, Strauss G, Rietschel S. 2015. Die Heteropterenfauna Kretas. Carolinea 73:83-130.

638 Halimi E, Paparisto A. 2014. A. Analysis of environmental factors in some ecosystems by 639 studying the distribution of species: plant bugs (Miridae). Proceeding of the 2nd 640 International Conference on Research and Education - "Challenges Toward the Future"

641

642 (ICRAE2014), 30-31 May 2014, University of Shkodra “Luigj Gurakuqi”, Shkodra,

643 Halimi E, Paparisto A, Topi D. 2014. Systematic and ecological analysis on plant bugs (Miridae, 644

645 Hemiptera) in the habitats of Lushnja region. Albanian Journal of Agricultural Science:

646 295-298.

647

Hanberry BB. 2013. Finer grain size increases effects of error and changes influence of

648 environmental predictors on species distribution models. Ecological informatics 15:8-13 https://doi.org/10.1016/j.ecoinf.2013.02.003.

649 Hubenov Z. 2008. Composition and zoogeographical characteristics of the family Tachinidae 650 (Diptera: Insecta) in Serbia and Bulgaria. Advances in Arachnology and Developmental Biology 12:375-394.

652 Jezkova T, Olah-Hemmings V, Riddle BR. 2011. Niche shifting in response to warming climate 653 after the last glacial maximum: inference from genetic data and niche assessments in the 654 chisel-toothed kangaroo rat (D ipodomys microps). Global Change Biology, 17(11), 3486655 3502 . 
656 Jueterbock A, Smolina I, Coyer JA, Hoarau G. 2016. The fate of the Arctic seaweed Fucus

657 distichus under climate change: an ecological niche modeling approach. Ecology and 658 evolution, 6(6), 1712-1724 https://doi.org/10.1002/ece3.2001.

659 Jueterbock, A. 2018. MaxentVariableSelection: Selecting the Best Set of Relevant

660 Environmental Variables along with the Optimal Regularization Multiplier for Maxent

$661 \quad$ Niche Modeling Available at https://cran.r-

662 project.org/web/packages/MaxentVariableSelection/MaxentVariableSelection.pdf

663 (accessed 15 April 2020).

664 Jung S, Kim J, Duwal RK. 2017. An annotated catalogue of the subfamily Orthotylinae

665 (Hemiptera: Heteroptera: Miridae) from the Korean Peninsula. Journal of Asia-Pacific

666 Biodiversity 10(3):403-408 https://doi.org/10.1016/j.japb.2017.05.006.

667 Kerzhner IM, Josifov M. 1999. Cimicomorpha II: Miridae. In: Aukema B, Rieger, C, ed.

668 Catalogue of the Heteroptera of the Palaearctic Region, Vol. 3. Amsterdam: Netherlands

669 Entomological Society, 1-577.

670 Kerzhner IM, Josifov M. 1999. Cimicomorpha II: Miridae. In: Aukema B, Rieger, C, ed.

671 Catalogue of the Heteroptera of the Palaearctic Region, Vol. 3. Amsterdam: Netherlands

672 Entomological Society, 1-577.

673 Knouft JH, Losos JB, Glor RE, Kolbe JJ. 2006. Phylogenetic analysis of the evolution of the

674 niche in lizards of the Anolis sagrei group. Ecology 87(7):S29-S38

675 https://doi.org/10.1890/0012-9658(2006)87[29:PAOTEO]2.0.CO;2.

676 Kment P, Baňař P. 2012. True bugs (Hemiptera: Heteroptera) of the Bílé Karpaty Protected

677 Landscape Area and Biosphere Reserve (Czech Republic). Acta Musei Moraviae, Scientiae 678 Biologicae 96(2):323-628.

679 Kondorosy, E. 2011. Keszthely és környéke poloskafaunájának alapvetése (Heteroptera). Folia

680 Musei Historico-Naturalis Bakonyiensis A Bakonyi Természettudományi múzeum

681 közleményei 28:105-145.

682 Konstantinov FV, Namyatova AA. 2019. Taxonomic Revisions and Specimen Databases in the

683 Internet Age: Dealing with a Species Rich Insect Taxon. Entomological Review 99(3):340-

$684 \quad 361 \mathrm{https} / / / \mathrm{doi} .0 \mathrm{~g} / 10.1134 / \mathrm{S} 0013873819030072$. 
685 Kozminykh VO, Naumkin DV. 2017. True heteropterans (Insecta: Heteroptera) of the Basegi 686 reserve and notes on heteropteran fauna of the Northern Urals. Fauna Urala and Sibiri 687 1:90-100 [In Russian].

688 Kozak KH, Wiens J. 2006. Does niche conservatism promote speciation? A case study in North 689 American salamanders. Evolution, 60(12):2604-2621 https://doi.org/10.1111/j.0014$690 \quad 3820.2006 . t b 01893 . x$.

691 Kozak KH, Wiens JJ. 2010. Accelerated rates of climatic-niche evolution underlie rapid species 692 diversification. Ecology letters 13(11):1378-1389 https://doi.org/10.1111/j.1461$693 \quad$ 0248.2010.01530.x.

694 Kramer-Schadt S, Niedballa J, Pilgrim JD, Schröder B, Lindenborn J, Reinfelder V, Stillfried M, 695 Heckman I, Scharf AK, Augeri DM, Cheyne SM, Hearn AJ, Ross J, Macdonald DW, 696 Mathai J, Eaton J, Marshall AJ, Semiadi G, Rustam R, Bernard H, Alfred R, Samejima H, 697

698 699

700 701

702

703

704

705

706

707

708

709

710

711

712 importance of correcting for sampling bias in MaxEnt species distribution models. Diversity and Distributions 19(11):1366-1379 https://doi.org/10.1111/ddi.12096.

Lim JS, Lee BW, Park SY, Jo DG. 2011. Insect fauna of Maebongsan mountain, Hongcheongun, Gangwon-do. Journal of Korean Nature 4(4):293-307 https://doi.org/10.7229/jkn.2011.4.4.293.

Lim JS, Park SY, Lee BW, Jo DG. 2012. A faunistic study of insects from Daebudo and Youngheungdo Islands in Korea. Journal of Korean Nature 5(4):311-325 https://doi.org/10.7229/jkn.2012.5.4.000.

Lim JS, Park SY, Lee BW. 2013a. A Study on the Insect Fauna in and Around Goseong-gun, Gangwon-do, South Korea. Journal of Asia-Pacific Biodiversity, 6(2), 221-237 http://dx.doi.org/10.7229/jkn.2013.6.2.221.

Lim JS, Park SY, Lim JO, Lee BW. 2013b. A Faunastic Study of Insects from Is. Ulleungdo and Its Nearby Islands in South Korea. Journal of Asia-Pacific Biodiversity 6(1):93-121 http://dx.doi.org/10.7229/jkn.2013.6.1.093.

Lisón F, Calvo JF. 2013. Ecological niche modelling of three pipistrelle bat species in semiarid Mediterranean landscapes. Acta Oecologica 47:68-73. 
714 Liu C, Newell G, White M. 2016. On the selection of thresholds for predicting species

715

716

717

718

719

720

721

722

723

724

725

726

727

728

729

730

731

732

733

734

735

736

737

738

739

740

741

742

743 occurrence with presence-only data. Ecology and evolution 6(1):337-348 https://doi.org/10.1002/ece3.1878.

López-Alvarez D, Manzaneda AJ, Rey PJ, Giraldo P, Benavente E, Allainguillaume J, Mur L, Caicedo AL, Hazen SP, Breiman A, Ezrati S, Catalán P. 2015. Environmental niche variation and evolutionary diversification of the Brachypodium distachyom grass complex species in their native circum-Mediterranean range. American Journal of Botany 102(7):1073-1088 https://doi.org10.3732/ajb.1500128.

Losos JB, Leal M, Glor RE, de Queiroz K, Hertz PE, Schettino LR, Lara AC, Jackman TR, Larson, A. 2003. Niche lability in the evolution of a Caribbean lizard community. Nature 424(6948):542-545.

Losos, JB. 2008. Phylogenetic niche conservatism, phylogenetic signal and the relationship between phylogenetic relatedness and ecological similarity among species. Ecology letters, 11(10), 995-1003 https://doi.org/10.1111/j.1461-0248.2008.01229.x.

McCormack JE, Zellmer AJ, \& Knowles LL. 2010. Does niche divergence accompany allopatric divergence in Aphelocoma jays as predicted under ecological speciation?: insights from tests with niche models. Evolution: International Journal of Organic Evolution, 64(5):1231-1244 DOI:10.1111/j.1558-5646.2009.00900.x.

Matocq A, Pluot-Sigwalt D, Özgen İ. 2014. Terrestrial Hemiptera (Heteroptera) collected in South-Eastern Anatolia (Diyarbakir, Mardin and Elaziğ provinces) (Turkey): second list. Munis Entomology \& Zoology 9(2):21-29.

Melber A, Günther H, Rieger C. 1991. Die Wanzenfauna des österreichischen Neusiedlerseegebietes (Insecta, Heteroptera). Wissenschaftliche Arbeiten aus dem Burgenland 89:63-192.

Merow C, Smith MJ, Silander JrJA. 2013. A practical guide to MaxEnt for modeling species' distributions: what it does, and why inputs and settings matter. Ecography 36(10):10581069 https://doi.org/10.1111/j.1600-0587.2013.07872.x.

Morales NS, Fernández IC, Baca-González V. 2017. MaxEnt's parameter configuration and small samples: are we paying attention to recommendations? A systematic review. PeerJ 5:e3093 DOI:10.7717/peerj.3093. 
744 Mudereri BT, Mukanga C, Mupfiga ET, Gwatirisa C, Kimathi E, Chitata T. 2020. Analysis of 745 potentially suitable habitat within migration connections of an intra-African migrant-the 746 Blue Swallow (Hirundo atrocaerulea). Ecological Informatics 57:101082 747 https://doi.org/10.1016/j.ecoinf.2020.101082.

748 Mumladze L. 2014. Sympatry without co-occurrence: exploring the pattern of distribution of two 749 750 Helix species in Georgia using an ecological niche modelling approach. Journal of 751 Molluscan Studies 80(3):249-255 https://doi.org/10.1093/mollus/eyu045.

Muscarella R, Galante PJ, Soley-Guardia M, Boria RA, Kass JM, Uriarte M, Anderson RP. 752 2014a. ENMeval: An R package for conducting spatially independent evaluations and 753 754 estimating optimal model complexity for Maxent ecological niche models. Methods in

755

756

757

758

759

760

761

762

763

764

765

766

767

768

769

770

771

772

773 Ecology and Evolution 5(11):1198-1205 https://doi.org/10.1111/2041-210X.12261.

Muscarella R, Kass JM, Galante R. 2014b. ENMeval Vignette. Available at https://cran.rproject.org/web/packages/ENMeval/vignettes/ENMeval-vignette.html\#block (accessed 15 April 2020).

Nagy, J., Végvári, Z., \& Varga, Z. (2017). Life history traits, bioclimate, and migratory systems of accipitrid birds of prey (Aves: Accipitriformes). Biological Journal of the Linnean Society, 121(1), 63-71.

Namyatova AA, Konstantinov FV. 2009. Revision of the genus Orthocephalus Fieber, 1858 (Hemiptera: Heteroptera: Miridae: Orthotylinae). Zootaxa 2316(1):1-118.

Nikolaeva AM. 2011. The preliminary list of the terrestrial heteropteran species (Insecta: Heteroptera) of the Mescchera National Park. Trudy Mordovskogo gosudarstvennogo prirodnogo zapovednika imeni P.G. Smidovicha 14:316-322 [In Russian].

Papeş M, Gaubert P. 2007. Modelling ecological niches from low numbers of occurrences: assessment of the conservation status of poorly known viverrids (Mammalia, Carnivora) across two continents. Diversity and distributions 13(6):890-902 https://doi.org/10.1111/j.1472-4642.2007.00392.x.

Park SJ, Kwon H, Park SK, Park DS. 2013. Comparative Insect Faunas between Ganghwado and Six Others Islands of West Coastal in Incheon, Korea. Journal of Asia-Pacific Biodiversity 6(2):197-219 https://doi.org/10.7229/jkn.2013.6.2.197.Pearson RG, Raxworthy CJ, Nakamura M, Peterson TA. 2007. Predicting species distributions from small numbers of 
774

775

776

777

778

779

780

781

782

783

784

785

786

787

788

789

790

791

792

793

794

795

796

797

798

799

800

801

802

803

occurrence records: a test case using cryptic geckos in Madagascar. Journal of biogeography 34(1):102-117 https://doi.org/10.1111/j.1365-2699.2006.01594.x.

Phillips SJ, Anderson RP, Schapire RE. 2006. Maximum entropy modeling of species geographic distributions. Ecological modelling 190(3-4):231-259 https://doi.org/10.1016/j.ecolmodel.2005.03.026.

Phillips SJ, Dudík M. 2008. Modeling of species distributions with MaxEnt: new extensions and a comprehensive evaluation. Ecography 31:161-175 https://doi.org/10.1111/j.09067590.2008.5203.x.

Phillips SJ, Dudík M, Elith J, Graham CH, Lehmann A, Leathwick J, Ferrier S. 2009. Sample selection bias and presence-only distribution models: implications for background and pseudo-absence data. Ecological applications 19(1):181-197 https://doi.org/10.1890/072153.1.

Porretta D, Mastrantonio V, Amendolia S, Gaiarsa, S, Epis S, Genchi C, Bandi C, Otranto D, Urbanelli, S. (2013). Effects of global changes on the climatic niche of the tick Ixodes ricinus inferred by species distribution modelling. Parasites \& Vectors 6(1): 271.

Potikha EV. 2015. A Taxonomic List of the Mayflies, Stoneflies and Caddisflies (Insecta: Ephemeroptera, Plecoptera and Trichoptera) of the Sikhote-Alin Biosphere Reserve. Achievements in the Life Sciences,9(1): 22-31 https://doi.org/10.1016/j.als.2015.05.004

Proosdij, van AS, Sosef MS, Wieringa JJ, Raes N. 2016. Minimum required number of specimen records to develop accurate species distribution models. Ecography 39(6):542-552 https://doi.org/10.1111/ecog.01509

Ribes, J. 1989. Mescellinea Fauna Iberica. (Heteroptera). Sessió Conjunta d'Entomologia, VI:1935.

Ripley B, Venables B, Bates DM, Hornik K, Gebhardt A, Firth D. 2020. Package "MASS". Available at https://cran.r-project.org/web/packages/MASS/MASS.pdf (accessed 15 April 2020).Roháčová M. 2007. Ploštice (Heteroptera) Přírodní památky Kamenná u Staříče po dvaceti letech True bugs (Heteroptera) of the Natural Monument Kamenná after twenty years. Práce a Studie Musea Beskyd, Přrirodní Vědy (Frýdek-Místek) 15:043-058.

Sánchez-García FJ, Galián J, Gallego, D. 2015. Distribution of Tomicus destruens (Coleoptera: Scolytinae) mitochondrial lineages: phylogeographic insights and niche 
804

805

806

807

808

809

810

811

812

813

814

815

816

817

818

819

820

821

822

823

824

825

826

827

828

829

830

831

832

833

834

modelling. Organisms Diversity \& Evolution 15(1):101-113

https://doi.org/10.1007/s13127-014-0186-2.

Schmitt T. 2007. Molecular biogeography of Europe: Pleistocene cycles and postglacial trends. Frontiers in zoology, 4(1), 11 https://doi.org/10.1186/1742-9994-4-11.

Seo C, Thorne JH, Hannah L, Thuiller W. 2009. Scale effects in species distribution models: implications for conservation planning under climate change. Biology letters 5(1):39-43 https://doi.org/10.1098/rsbl.2008.0476.

Shi K, Li Y, Bao C. 2016. Study on Species Diversity, Zoogeographical Distribution and Ecological Properties of the Miridae (Hemiptera) Family in the Hulun Buir City, Inner Mongolia of China. International Proceedings of Chemical, Biological and Environmental Engineering 91:43-47.

Shcheglovitova M, Anderson RP. 2013. Estimating optimal complexity for ecological niche models: a jackknife approach for species with small sample sizes. Ecological Modelling 269:9-17 https://doi.org/10.1016/j.ecolmodel.2013.08.011.

Sofronova EV. 2017. The true bugs (Hemiptera, Heteroptera) of the Baykalo-Lenskiy Reserve with new records from Irkutskaya Oblast'in East Siberia, Russia. Euroasian Entomological Journal 16(3):207-212 [In Russian].

Tamanini L. 1981. Gli eterotteri della Basilicata e della Calabria (Italia meridionale) (Hemiptera, Heteroptera). Memorie del Museo civico di storia naturale di Verona, ser. 2, A 3:1-164.

Taszakowski A, Pasińska A. 2017. New data on the occurrence of terrestrial true bugs (Hemiptera: Heteroptera) in Pieniny Mountains. Fragmenta Faunistica 60(1):15-22.

Tóth JP, Varga K, Végvári Z, Varga Z. 2013. Distribution of the Eastern knapweed fritillary (Melitaea ornata Christoph, 1893) (Lepidoptera: Nymphalidae): past, present and future. Journal of Insect Conservation 17(2):245-255 https://doi.org/10.1007/s10841-0129503-2.

Vinokurov NN, Golub VB, Zinovjeva AN. 2017. Plant bugs (Heteroptera, Miridae) of the South Urals State Nature Reserve. II. Orthotylinae, Phylinae. Euroasian Entomological Journal $16(3): 247-252$.

Vinokurov NN, Kanyukova EV, Ostapenko KA, 2016 Homoptera (Cicadina) and Heteroptera of the Sikhote-Alin State Nature Biosphere reserve. Amurian Zoological Journal 8(4):233249 [In Russian].

Peer) reviewing PDF | (2020:04:48200:2:1:NEW 14 Nov 2020) 
835 Wagner E. 1974. Die Miridae Hahn, 1831, des Mittelmeerraumes und der Makaronesischen 836 Inseln (Hemiptera, Heteroptera). Teil 2. Entomologische Abhandlungen. Leipzig:

837 Akademische Verlagsgesellschaft Geest \& Portig.

838 Wagner E, Weber HH. 1965. Héteroptères Miridae. Faune de France 67: 1-592.

839 Wellenreuther M, Larson KW, Svensson EI. 2012. Climatic niche divergence or conservatism?

840 Environmental niches and range limits in ecologically similar

841 damselflies. Ecology 93(6):1353-1366.

842 Wiens JJ., Ackerly DD, Allen AP, Anacker BL, Buckley LB, Cornell HV, Damschen EI, Davis

843 TJ, Grytnes J, Harrison SP, Hawkins BA, Halt RD, McCain CM, Stephens PR. 2010.

$844 \quad$ Niche conservatism as an emerging principle in ecology and conservation

845 biology. Ecology letters, 13(10), 1310-1324 https://doi.org/10.1111/j.1461-

$846 \quad$ 0248.2010.01515.x.

847 Warren, D. L., Glor, R. E., \& Turelli, M. (2010). ENMTools: a toolbox for comparative studies

848 of environmental niche models. Ecography, 33(3), 607-611 https://doi.org/10.1111/j.1600-

$849 \quad$ 0587.2009.06142.x.

850

851 


\section{Table 1 (on next page)}

Variables, contributing to the models CF (first column for each species) and CR model (second column for each species).

The variables used for modelling are marked with " $\mathrm{X}$ ". PC and PI denote the variables having PC and PI higher than 10\%. Total area of the suitable conditions projected area for each model is provided in the last raw. 
Table 1:

2 Variables, contributing to the models CF (first column for each species) and CR model (second column for each species). The

3 variables used for modelling are marked with "X". PC and PI denote the variables having PC and PI higher than 10\%. Total area of

4 the suitable conditions projected area for each model is provided in the last raw.

\begin{tabular}{|c|c|c|c|c|c|c|c|c|c|c|c|c|c|c|c|c|}
\hline & \multicolumn{2}{|c|}{ bivittatus } & \multicolumn{2}{|l|}{ brevis } & \multicolumn{2}{|c|}{ coriaceus } & \multicolumn{2}{|c|}{ fulvipes } & \multicolumn{2}{|c|}{ funestus } & \multicolumn{2}{|c|}{ proserpinae } & \multicolumn{2}{|c|}{ saltator } & \multicolumn{2}{|c|}{ vittipennis } \\
\hline & CF & CR & CF & CR & CF & $\mathbf{C R}$ & CF & $\mathbf{C R}$ & CF & $\mathbf{C R}$ & CF & $\mathbf{C R}$ & $\mathbf{C F}$ & $\mathbf{C R}$ & CF & $\mathbf{C R}$ \\
\hline Bio1 Annual Mean Temp & PC PI & PC PI & PC PI & PC PI & $\mathrm{X}$ & & $\mathrm{X}$ & & PI & & $\mathrm{X}$ & & PI & & PC PI & $\mathrm{X}$ \\
\hline Bio2 Mean Diurnal Range & PI & & $\mathrm{X}$ & & $\mathrm{X}$ & $\mathrm{X}$ & $\mathrm{X}$ & & $\mathrm{X}$ & $\mathrm{X}$ & $\mathrm{X}$ & & $\mathrm{X}$ & $\mathrm{X}$ & $\mathrm{X}$ & $\mathrm{PC}$ \\
\hline Bio3 Isothermality & PI & $\mathrm{X}$ & $\mathrm{X}$ & & PC PI & PC PI & $\mathrm{X}$ & & PC PI & PC PI & $\mathrm{X}$ & & $\mathrm{X}$ & $\mathrm{X}$ & $X$ & $\mathrm{X}$ \\
\hline Bio4 Temp Seasonality & PI & $\mathrm{X}$ & $\mathrm{X}$ & & $\mathrm{X}$ & & $\mathrm{X}$ & & $\mathrm{X}$ & & PI & PC PI & $\mathrm{X}$ & $\mathrm{X}$ & $X$ & \\
\hline $\begin{array}{l}\text { Bio5 Max Temp of } \\
\text { Warmest Month }\end{array}$ & $\mathrm{X}$ & & $\mathrm{X}$ & $\mathrm{X}$ & $\mathrm{X}$ & & $\mathrm{X}$ & $\mathrm{X}$ & $\mathrm{X}$ & & $\mathrm{X}$ & & $\mathrm{X}$ & $\mathrm{X}$ & $\mathrm{X}$ & \\
\hline $\begin{array}{l}\text { Bio6 Min Temp of Coldest } \\
\text { Month }\end{array}$ & $\mathrm{X}$ & & $\mathrm{X}$ & & $\mathrm{X}$ & & $\mathrm{X}$ & PI & $\mathrm{X}$ & PC PI & $\mathrm{X}$ & & PI & PC PI & $\mathrm{X}$ & \\
\hline Bio7 Temp Annual Range & PI & & $\mathrm{X}$ & & $\mathrm{X}$ & & $\mathrm{X}$ & & $\mathrm{X}$ & & PC PI & $\mathrm{X}$ & PI & & $\mathrm{X}$ & PC PI \\
\hline $\begin{array}{l}\text { Bio8 Mean Temp of Wettest } \\
\text { Quarter }\end{array}$ & $\mathrm{X}$ & $\mathrm{X}$ & $\mathrm{X}$ & & $\mathrm{X}$ & & $\mathrm{X}$ & & $\mathrm{X}$ & & $\mathrm{X}$ & & $\mathrm{X}$ & $\mathrm{X}$ & $\mathrm{X}$ & $\mathrm{X}$ \\
\hline $\begin{array}{l}\text { Bio9 Mean Temp of Driest } \\
\text { Quarter }\end{array}$ & $\mathrm{X}$ & $\mathrm{PC}$ & $\mathrm{X}$ & $\mathrm{X}$ & $\mathrm{X}$ & & PC PI & & $\mathrm{X}$ & & PC PI & & $\mathrm{X}$ & $\mathrm{X}$ & $\mathrm{PC}$ & PI \\
\hline $\begin{array}{l}\text { Bio10 Mean Temp of } \\
\text { Warmest Quarter }\end{array}$ & $\mathrm{X}$ & $\mathrm{PC}$ & $\mathrm{X}$ & & $\mathrm{X}$ & & $\mathrm{X}$ & & $\mathrm{X}$ & $\mathrm{PC}$ & $\mathrm{X}$ & & $\mathrm{X}$ & & $\mathrm{X}$ & $\mathrm{X}$ \\
\hline $\begin{array}{l}\text { Bio11 Mean Temp of } \\
\text { Coldest Quarter }\end{array}$ & $\mathrm{PC}$ & & $\mathrm{X}$ & & PI & & $\mathrm{X}$ & & $\mathrm{X}$ & & $\mathrm{X}$ & & $\mathrm{PC}$ & & PI & \\
\hline Bio12 Annual Precipitation & $\mathrm{X}$ & & $\mathrm{X}$ & $\mathrm{X}$ & $\mathrm{X}$ & & $\mathrm{X}$ & & $\mathrm{X}$ & & $X$ & & $\mathrm{X}$ & $\mathrm{X}$ & $\mathrm{X}$ & \\
\hline $\begin{array}{l}\text { Bio13 Precipitation of } \\
\text { Wettest Month }\end{array}$ & $\mathrm{X}$ & $\mathrm{X}$ & $\mathrm{X}$ & $\mathrm{X}$ & $\mathrm{X}$ & & $\mathrm{X}$ & & $\mathrm{X}$ & & $\mathrm{X}$ & & $\mathrm{X}$ & $\mathrm{X}$ & $\mathrm{X}$ & \\
\hline $\begin{array}{l}\text { Bio14 Precipitation of } \\
\text { Driest Month }\end{array}$ & $\mathrm{X}$ & $\mathrm{X}$ & PC PI & PC PI & $\mathrm{PC}$ & $\mathrm{PC}$ & $\mathrm{X}$ & & $\mathrm{X}$ & & $\mathrm{PC}$ & $\mathrm{PC}$ & $\mathrm{X}$ & $\mathrm{X}$ & $\mathrm{X}$ & $\mathrm{X}$ \\
\hline $\begin{array}{l}\text { Bio15 Precipitation } \\
\text { Seasonality }\end{array}$ & $\mathrm{PC}$ & $\mathrm{PC}$ & $\mathrm{X}$ & PI & PI & & $\mathrm{X}$ & & $\mathrm{X}$ & PC PI & $\mathrm{X}$ & $\mathrm{X}$ & $\mathrm{X}$ & $\mathrm{X}$ & $\mathrm{X}$ & $\mathrm{X}$ \\
\hline $\begin{array}{l}\text { Bio16 Precipitation of } \\
\text { Wettest Quarter }\end{array}$ & $\mathrm{X}$ & & $\mathrm{X}$ & & $\mathrm{X}$ & PI & $\mathrm{X}$ & PC PI & PI & & $\mathrm{X}$ & & $\mathrm{X}$ & & $\mathrm{X}$ & $\mathrm{PC}$ \\
\hline $\begin{array}{l}\text { Bio17 Precipitation of } \\
\text { Driest Quarter }\end{array}$ & $\mathrm{X}$ & & $X$ & & $X$ & & $X$ & & $X$ & PC PI & $X$ & & $\mathrm{X}$ & & $\mathrm{X}$ & \\
\hline $\begin{array}{l}\text { Bio18 Precipitation of } \\
\text { Warmest Quarter }\end{array}$ & $X$ & PC PI & $\mathrm{X}$ & $\mathrm{X}$ & $\mathrm{X}$ & $X$ & PC PI & PC PI & $\mathrm{PC}$ & & $\mathrm{X}$ & & $\mathrm{X}$ & $\mathrm{X}$ & $\mathrm{X}$ & PC PI \\
\hline $\begin{array}{l}\text { Bio19 Precipitation of } \\
\text { Coldest Quarter }\end{array}$ & $\mathrm{X}$ & $\mathrm{X}$ & $\mathrm{X}$ & & $\mathrm{PC}$ & $\mathrm{PC}$ & PC PI & & $\mathrm{X}$ & & $\mathrm{PC}$ & PC PI & $\mathrm{X}$ & $\mathrm{PC}$ & $\mathrm{X}$ & $\mathrm{X}$ \\
\hline
\end{tabular}


Area $\left(\times 10^{6} \mathrm{~km}^{2}\right)$

\begin{tabular}{|l|l|l|}
\hline 9.65 & 8.05 \\
\hline
\end{tabular}

\begin{tabular}{|l|l|l|l|l|l|}
\hline 8.78 & 8.62 & 8.19 & 5.08 & 8.11 & 5.76 \\
\hline
\end{tabular}

\begin{tabular}{|l|l|l}
\hline 5.41 & 3.56 & 1
\end{tabular}

\begin{tabular}{|l|l|l|l|l|l|}
\hline 1.83 & 1.73 & 10.06 & 10.10 & 13.67 & 12.97 \\
\hline
\end{tabular}




\section{Table 2 (on next page)}

Niche overlap (in bold), identity test and background test results.

The results for the I and D metrics are separated with the bold line. If the niche overlap values are significantly lower than $5 \%$ threshold for permuted values, this means that the models are different. If the niche overlap values are higher or lower than those from background test, this means that the niches are more similar or more different than expected from random data respectively. 
Table 2:

Niche overlap (in bold), identity test and background test results. The results for the I and D metrics are separated with the bold line. If the niche overlap values are significantly lower than $5 \%$ threshold for permuted values, this means that the models are different. If the niche overlap values are higher or lower than those from background test, this means that the niches are more similar or more different than expected from random data respectively.

\begin{tabular}{|c|c|c|c|c|c|c|c|c|c|c|}
\hline & $\begin{array}{l}\text { Niche } \\
\text { overlap I } \\
\text { (CF } \\
\text { models) }\end{array}$ & $\begin{array}{l}\text { Niche } \\
\text { overl } \\
\text { ap I } \\
\text { (CR } \\
\text { mode } \\
\text { ls) }\end{array}$ & $\begin{array}{l}\text { Identity } \\
\text { test } 5 \% \\
\text { threshold } \\
\text { for } \\
\text { permuted } \\
\text { I values }\end{array}$ & $\begin{array}{l}\text { Backgro } \\
\text { und test I } \\
\text { values, } \\
\text { forward } \\
\text { comparis } \\
\text { on }\end{array}$ & $\begin{array}{l}\text { Backgr } \\
\text { ound } \\
\text { test I } \\
\text { values, } \\
\text { reverse } \\
\text { compar } \\
\text { ison }\end{array}$ & $\begin{array}{l}\text { Niche } \\
\text { overla } \\
\text { p D } \\
\text { (CF } \\
\text { models } \\
\text { ) }\end{array}$ & $\begin{array}{l}\text { Niche } \\
\text { overl } \\
\text { ap D } \\
\text { (CR } \\
\text { mode } \\
\text { ls) }\end{array}$ & $\begin{array}{l}\text { Identity } \\
\text { test 5\% } \\
\text { thresho } \\
\text { ld for } \\
\text { permut } \\
\text { ed D } \\
\text { values }\end{array}$ & $\begin{array}{l}\text { Backgr } \\
\text { ound } \\
\text { test D } \\
\text { values, } \\
\text { forward } \\
\text { compar } \\
\text { ison }\end{array}$ & $\begin{array}{l}\text { Backgr } \\
\text { ound } \\
\text { test D } \\
\text { values, } \\
\text { reverse } \\
\text { compar } \\
\text { ison }\end{array}$ \\
\hline bivittatus vs brevis & 0.802 & 0.815 & 0.96 & 0.623 & 0.615 & 0.549 & 0.555 & 0.824 & 0.330 & 0.336 \\
\hline bivittatus vs coriaceus & 0.7 & 0.628 & 0.928 & 0.626 & 0.536 & 0.39 & 0.326 & 0.735 & 0.334 & 0.257 \\
\hline bivittatus vs fulvipes & 0.42 & 0.614 & 0.9 & 0.626 & 0.397 & 0.19 & 0.318 & 0.66 & 0.333 & 0.168 \\
\hline bivittatus vs funestus & 0.504 & 0.649 & 0.95 & 0.634 & 0.433 & 0.28 & 0.373 & 0.78 & 0.34 & 0.204 \\
\hline bivittatus vs proserpinae & 0.324 & 0.375 & 0.953 & 0.619 & 0.285 & 0.141 & 0.174 & 0.776 & 0.327 & 0.106 \\
\hline bivittatus vs saltator & 0.854 & 0.83 & 0.968 & 0.622 & 0.613 & 0.593 & 0.575 & 0.838 & 0.329 & 0.337 \\
\hline bivittatus vs vittipennis & 0.812 & 0.748 & 0.97 & 0.619 & 0.694 & 0.56 & 0.479 & 0.835 & 0.327 & 0.404 \\
\hline brevis vs coriaceus & 0.836 & 0.798 & 0.902 & 0.608 & 0.540 & 0.522 & 0.485 & 0.69 & 0.332 & 0.259 \\
\hline brevis vs fulvipes & 0.271 & 0.651 & 0.847 & 0.597 & 0.398 & 0.08 & 0.366 & 0.623 & 0.323 & 0.168 \\
\hline brevis vs funestus & 0.79 & 0.814 & 0.94 & 0.614 & 0.439 & 0.505 & 0.539 & 0.78 & 0.335 & 0.208 \\
\hline brevis vs proserpinae & 0.376 & 0.416 & 0.862 & 0.603 & 0.293 & 0.158 & 0.186 & 0.636 & 0.328 & 0.11 \\
\hline brevis vs saltator & 0.905 & 0.929 & 0.961 & 0.615 & 0.618 & 0.724 & 0.758 & 0.818 & 0.335 & 0.342 \\
\hline brevis vs vittipennis & 0.912 & 0.867 & 0.96 & 0.612 & 0.694 & 0.677 & 0.618 & 0.823 & 0.332 & 0.404 \\
\hline coriaceus vs fulvipes & 0.397 & 0.697 & 0.87 & 0.522 & 0.382 & 0.169 & 0.378 & 0.633 & 0.248 & 0.161 \\
\hline coriaceus vs funestus & 0.493 & 0.473 & 0.906 & 0.538 & 0.436 & 0.236 & 0.21 & 0.689 & 0.258 & 0.208 \\
\hline coriaceus vs proserpinae & 0.533 & 0.579 & 0.863 & 0.526 & 0.287 & 0.276 & 0.292 & 0.625 & 0.251 & 0.108 \\
\hline coriaceus vs saltator & 0.854 & 0.833 & 0.915 & 0.538 & 0.621 & 0.57 & 0.538 & 0.723 & 0.257 & 0.347 \\
\hline coriaceus vs vittipennis & 0.723 & 0.723 & 0.930 & 0.531 & 0.699 & 0.41 & 0.389 & 0.748 & 0.253 & 0.411 \\
\hline fulvipes vs funestus & 0.105 & 0.532 & 0.846 & 0.394 & 0.418 & 0.223 & 0.267 & 0.602 & 0.167 & 0.195 \\
\hline fulvipes vs proserpinae & 0.76 & 0.711 & 0.841 & 0.397 & 0.282 & 0.484 & 0.267 & 0.593 & 0.168 & 0.104 \\
\hline fulvipes vs saltator & 0.444 & 0.679 & 0.875 & 0.394 & 0.596 & 0.22 & 0.4 & 0.664 & 0.167 & 0.326 \\
\hline fulvipes vs vittipennis & 0.274 & 0.651 & 0.882 & 0.386 & 0.687 & 0.09 & 0.337 & 0.662 & 0.161 & 0.4 \\
\hline funestus vs proserpinae & 0.181 & 0.231 & 0.824 & 0.417 & 0.292 & 0.062 & 0.076 & 0.564 & 0.195 & 0.109 \\
\hline funestus vs saltator & 0.646 & 0.713 & 0.951 & 0.435 & 0.618 & 0.366 & 0.431 & 0.791 & 0.206 & 0.343 \\
\hline funestus vs vittipennis & 0.749 & 0.828 & 0.952 & 0.435 & 0.692 & 0.467 & 0.552 & 0.793 & 0.206 & 0.402 \\
\hline
\end{tabular}


proserpinae vs saltator

proserpinae vs vittipennis

0.493
0.320

$\mathbf{0 . 3 2 0}$

0.846

\begin{tabular}{l|l|l|l|l|}
$\mathbf{0 . 5 3 3}$ & 0.867 & 0.296 & 0.604 & $\mathbf{0 . 2 5 3}$ \\
$\mathbf{0 . 3 9 7}$ & 0.877 & 0.296 & 0.685 & $\mathbf{0 . 1 2 9}$ \\
$\mathbf{0 . 8 1 9}$ & 0.97 & 0.613 & 0.693 & $\mathbf{0 . 5 9 9}$ \\
\hline
\end{tabular}

\begin{tabular}{|l|l|}
$\mathbf{0 . 2 6 1}$ & 0.627 \\
\hline $\mathbf{0 . 1 7 3}$ & 0.662 \\
\hline
\end{tabular}

\begin{tabular}{l|l}
$\mathbf{0 . 5 7 3}$ & 0.84
\end{tabular}

\begin{tabular}{|l|l|}
\hline 0.11 & 0.331 \\
\hline 0.111 & 0.397 \\
\hline 0.338 & 0.403 \\
\hline
\end{tabular}

6

7 


\section{Figure 1}

Maps of records used in the analysis.

A. O. bivittatus, B. O. brevis, C. O. coriaceus, D. O. fulvipes. The background maps is taken from

https://github.com/nvkelso/natural-earth-quick-start/tree/master/50m_raster/NE1_50M_SR_W

. The layer with the country borders is taken from

https://github.com/petewarden/openheatmap/tree/master/mapfileprocess/test_data/TM_WOR LD_BORDERS-0.3. 


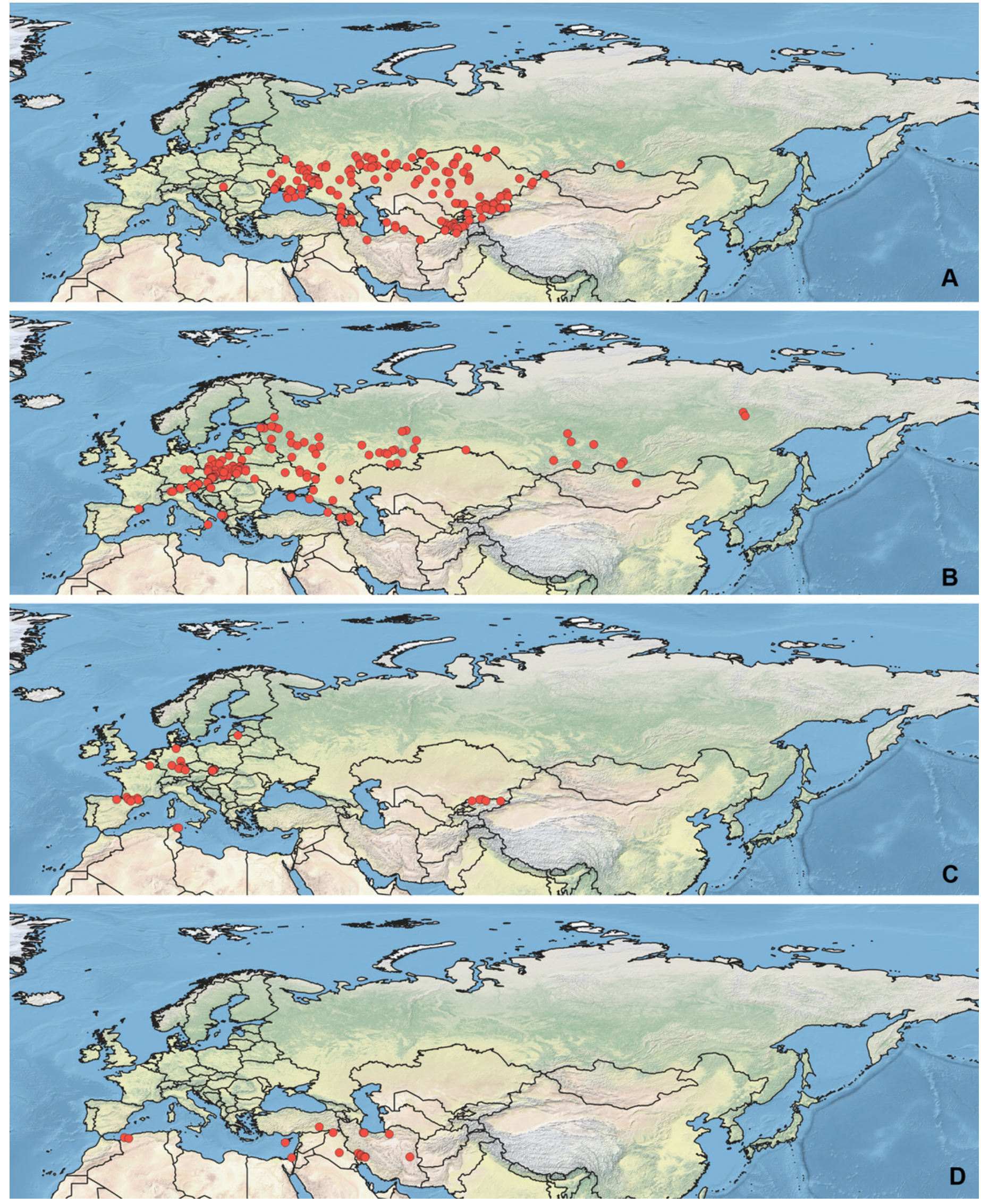


Figure 2

Maps of records used in the analysis

A. O. funestus, B. O. proserpinae, C. O. saltator, D. O. vittipennis. The background maps is taken from

https://github.com/nvkelso/natural-earth-quick-start/tree/master/50m_raster/NE1_50M_SR_W

. The layer with the country borders is taken from

https://github.com/petewarden/openheatmap/tree/master/mapfileprocess/test_data/TM_WOR

LD_BORDERS-0.3. 

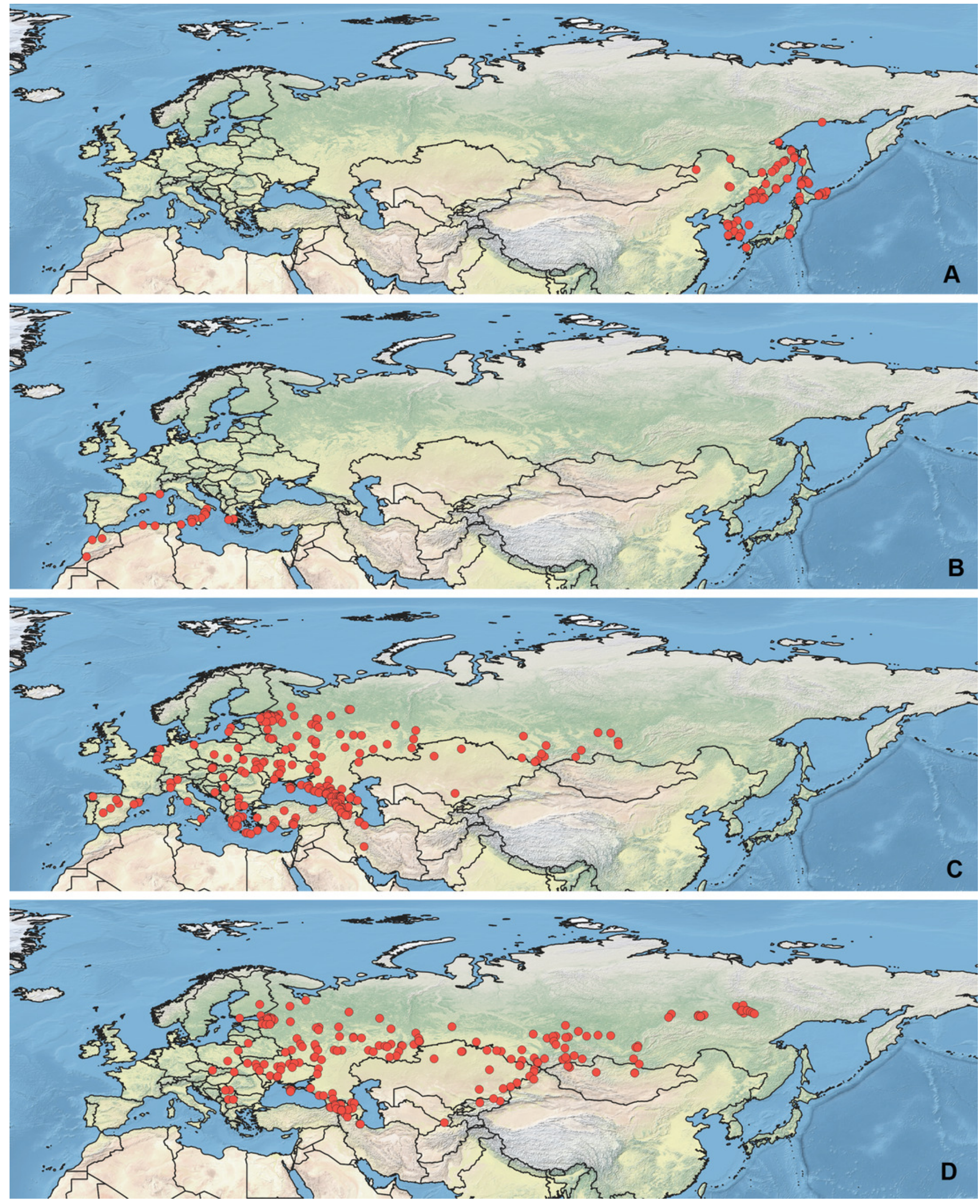


\section{Figure 3}

Geographical projections of the CF models.

A. O. bivittatus, B. O. brevis, C. O. coriaceus, D. O. fulvipes. Threshold is indicated with the black line. Colors correspond to the suitability score at the bottom of the figure, with 0 corresponding to the most unsuitable places and 1 corresponding to the most suitable places. The layer with the country borders is taken from https://github.com/petewarden/openheatmap/tree/master/mapfileprocess/test_data/TM_WOR LD BORDERS-0.3. 

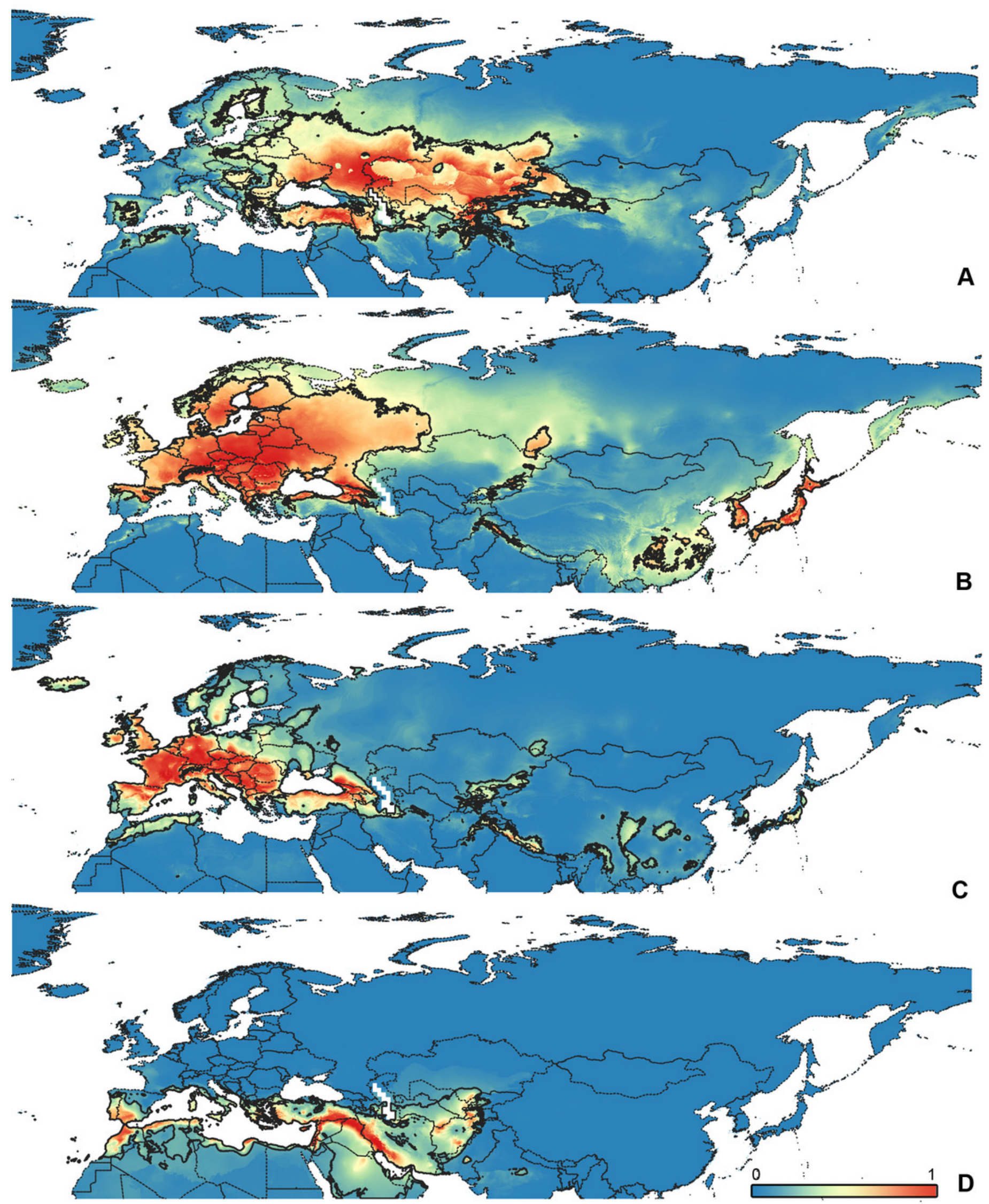


\section{Figure 4}

Geographical projections of the CR models.

A. O. bivittatus, B. O. brevis, C. O. coriaceus, D. O. fulvipes. Threshold is indicated with the black line. Colors correspond to the suitability score at the bottom of the figure, with 0 corresponding to the most unsuitable places and 1 corresponding to the most suitable places. The layer with the country borders is taken from https://github.com/petewarden/openheatmap/tree/master/mapfileprocess/test_data/TM_WOR LD_BORDERS-0.3. 


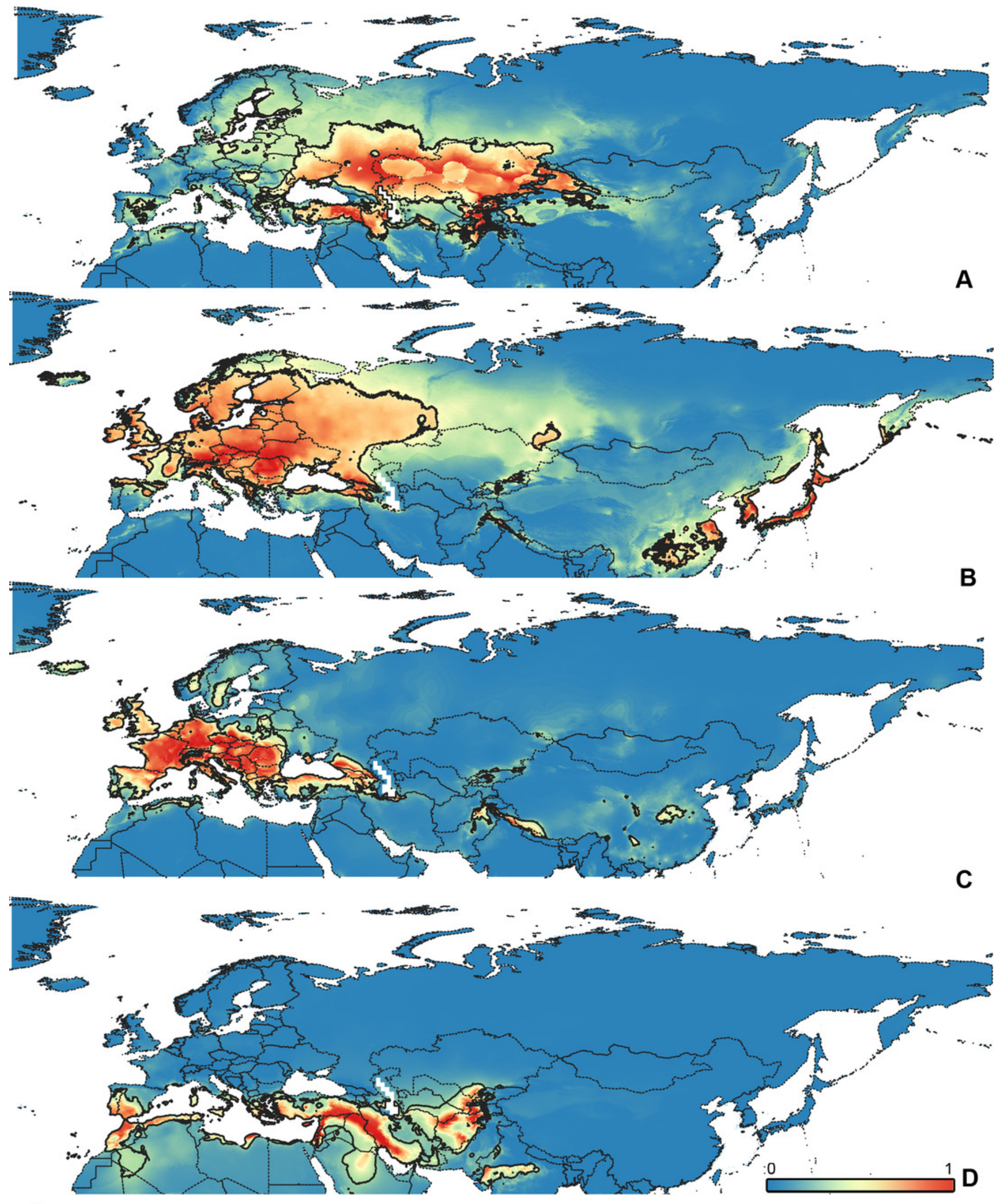




\section{Figure 5}

Geographical projections of the CF models.

A. O. funestus, B. O. proserpinae, C. O. saltator, D. O. vittipennis. Threshold is indicated with the black line. Colors correspond to the suitability score at the bottom of the figure, with 0 corresponding to the most unsuitable places and 1 corresponding to the most suitable places. The layer with the country borders is taken from https://github.com/petewarden/openheatmap/tree/master/mapfileprocess/test_data/TM_WOR LD_BORDERS-0.3. 

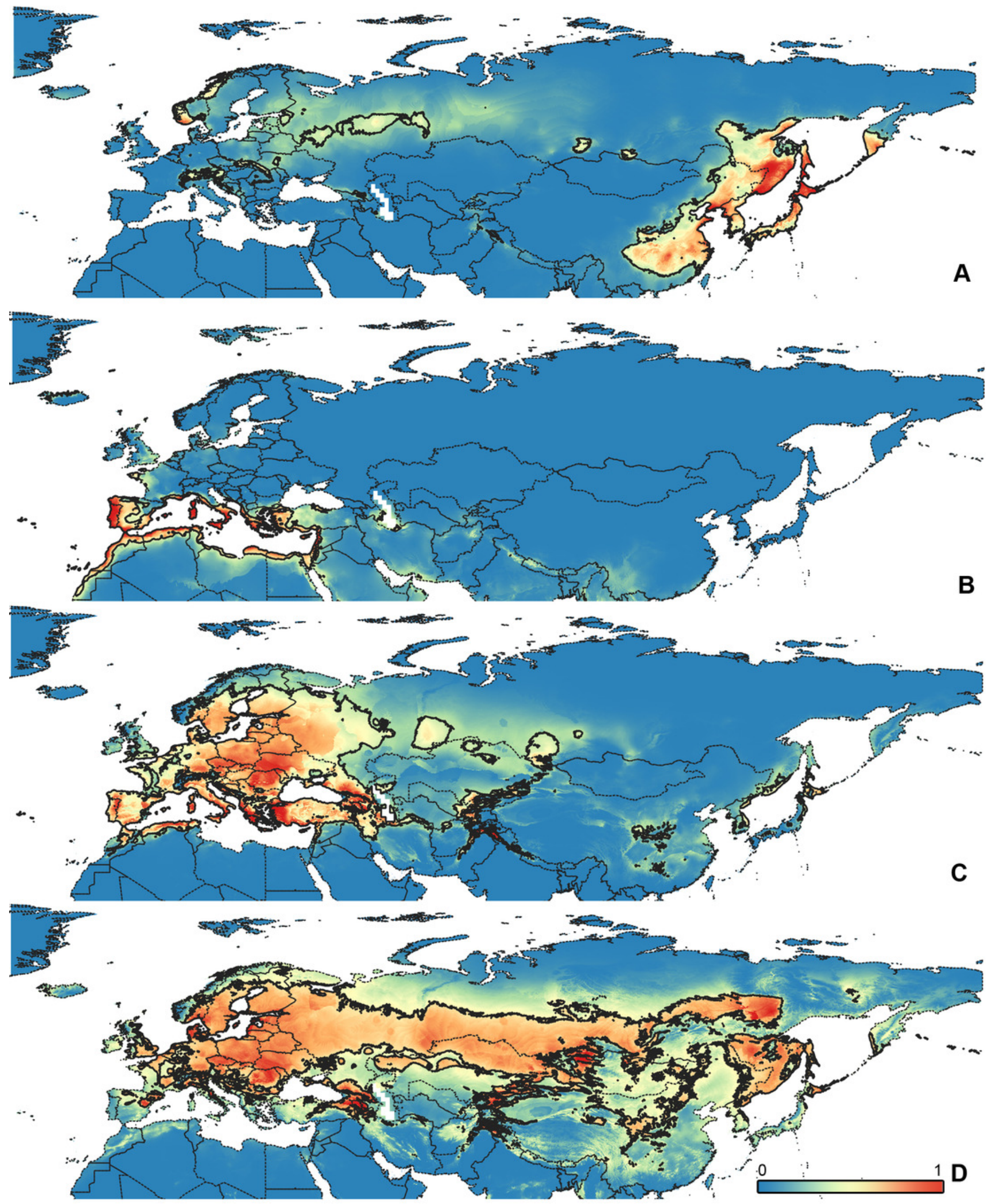


\section{Figure 6}

Geographical projections of the CR models.

A. O. funestus, B. O. proserpinae, C. O. saltator, D. O. vittipennis. Threshold is indicated with the black line. Colors correspond to the suitability score at the bottom of the figure, with 0 corresponding to the most unsuitable places and 1 corresponding to the most suitable places. The layer with the country borders is taken from https://github.com/petewarden/openheatmap/tree/master/mapfileprocess/test_data/TM_WOR LD_BORDERS-0.3. 


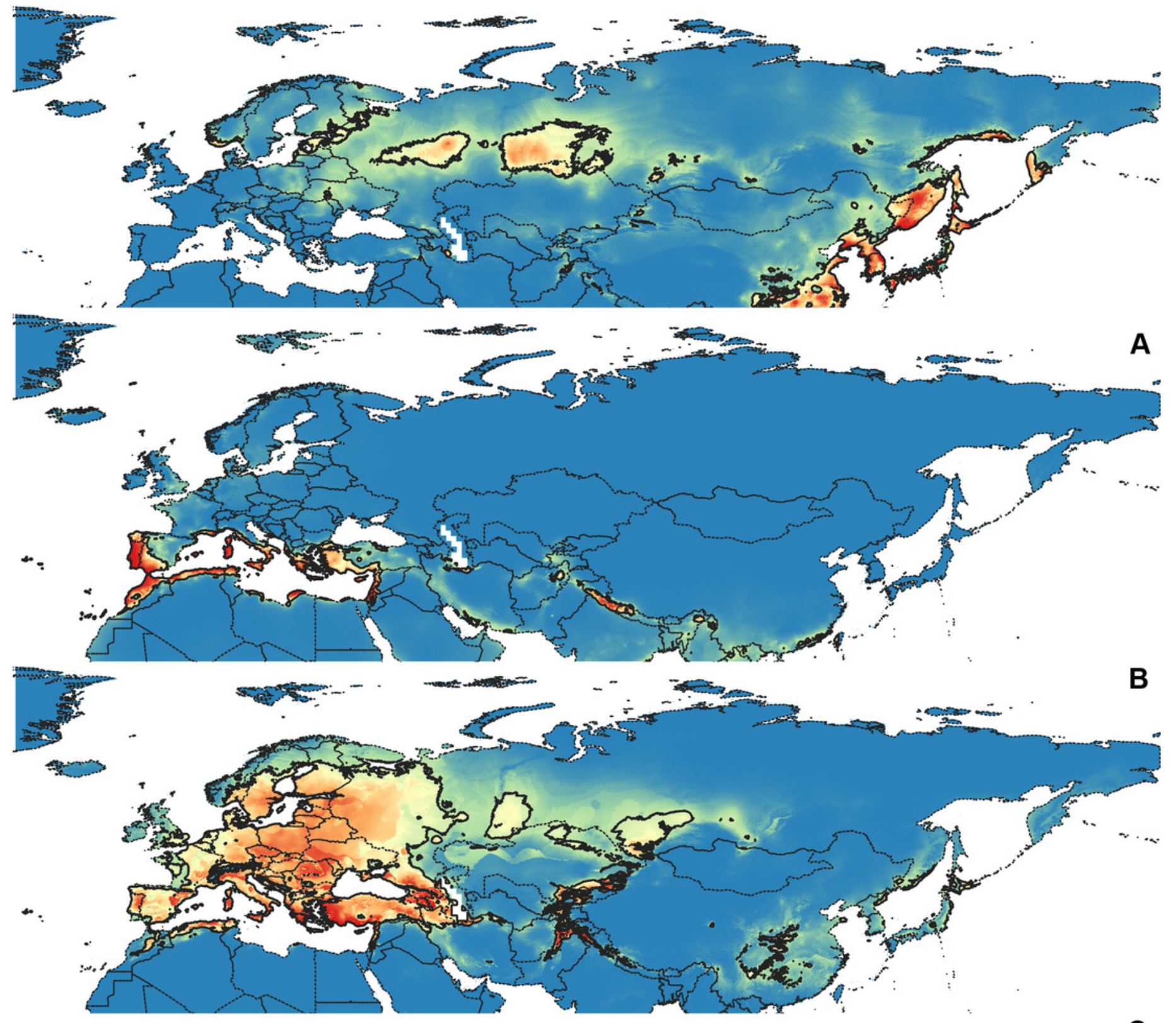

C

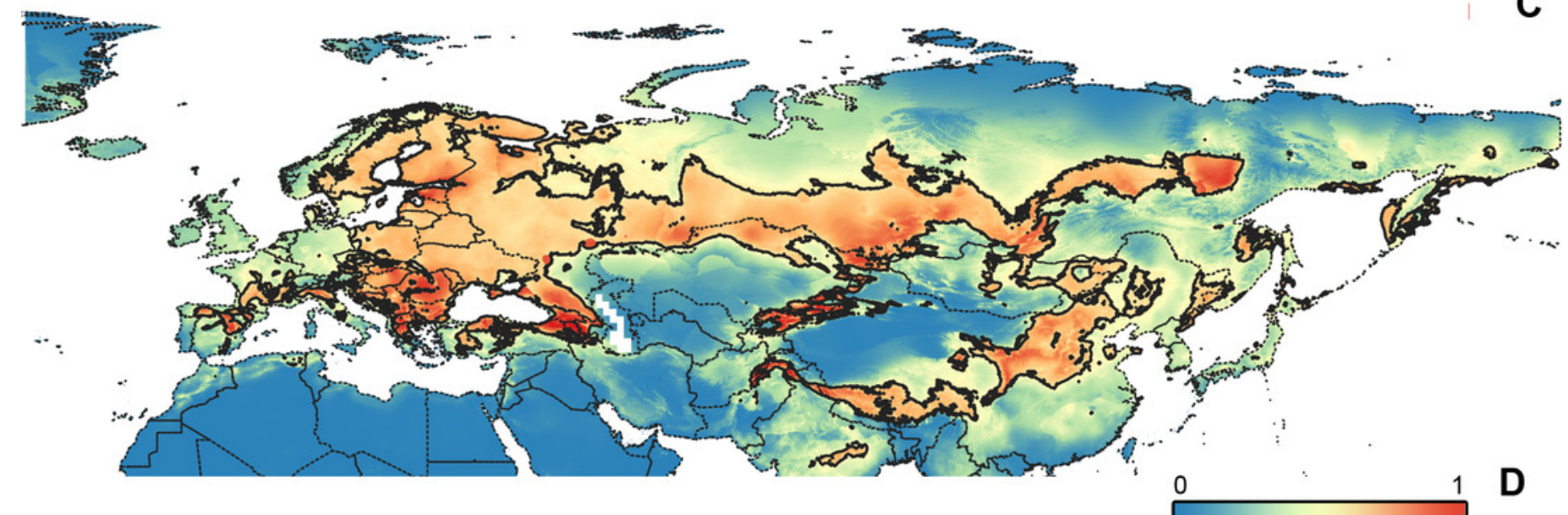


Figure 7

The ranges of bio1, bio2, bio3, and bio4.

For each species, the first (red) line corresponds to the CF model, the second (green) line corresponds to the CR model, and the third (blue) line corresponds to the actual records. 


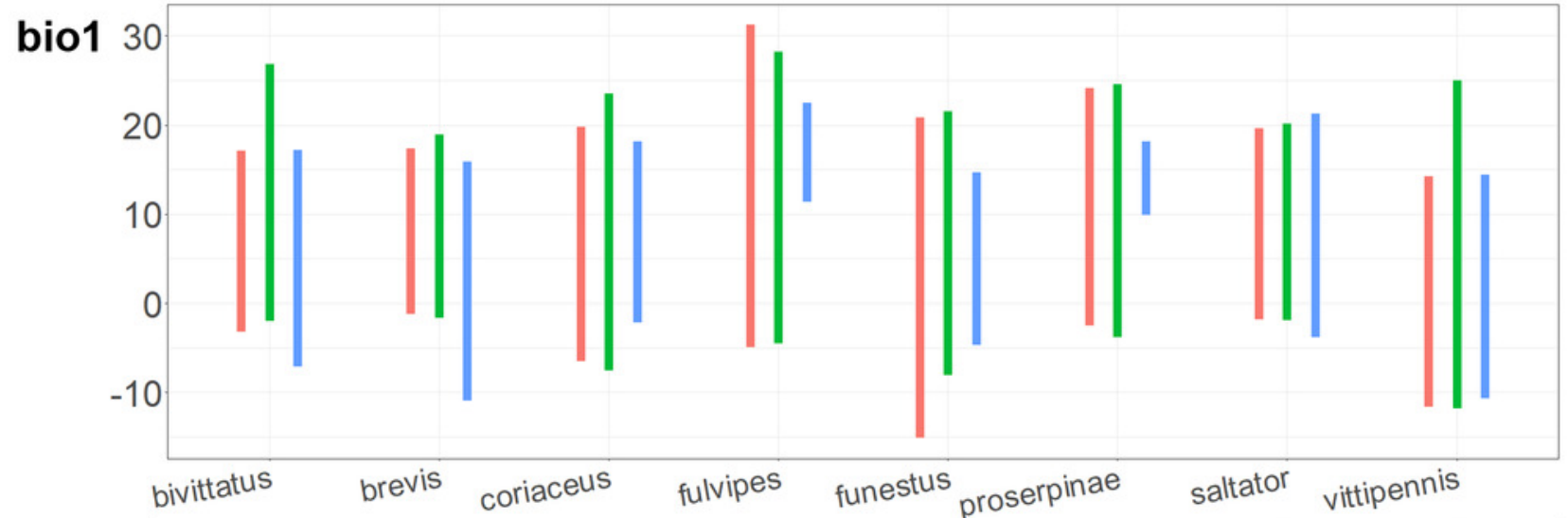

A

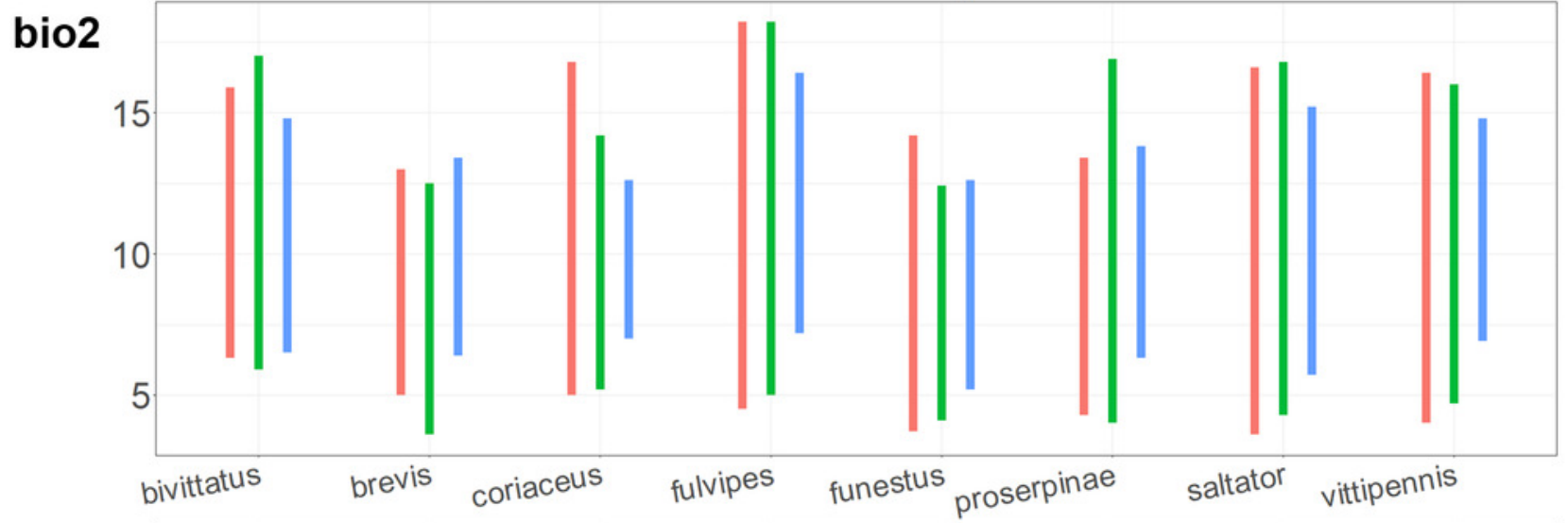

B

bio3 60
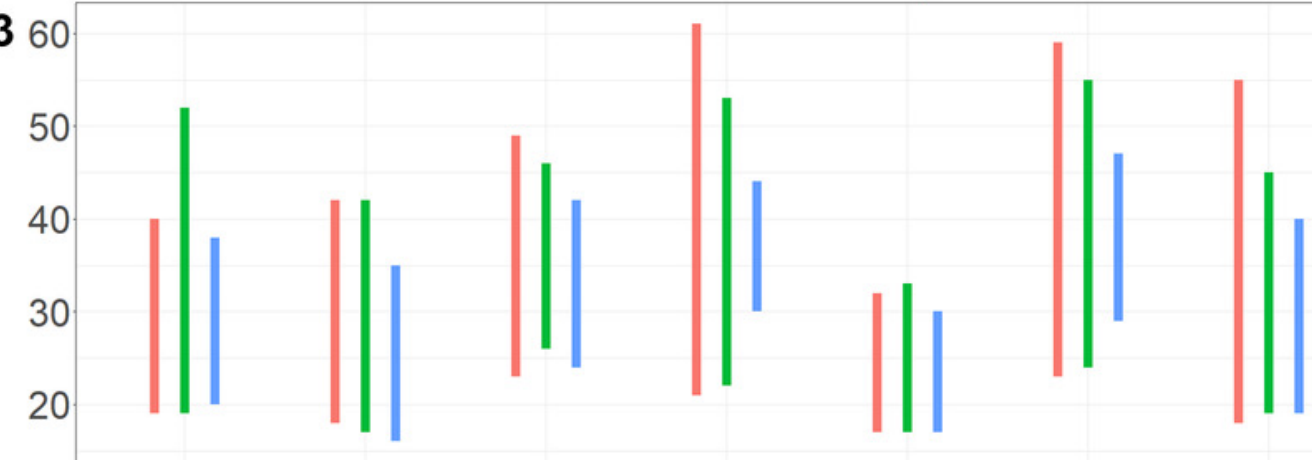

C
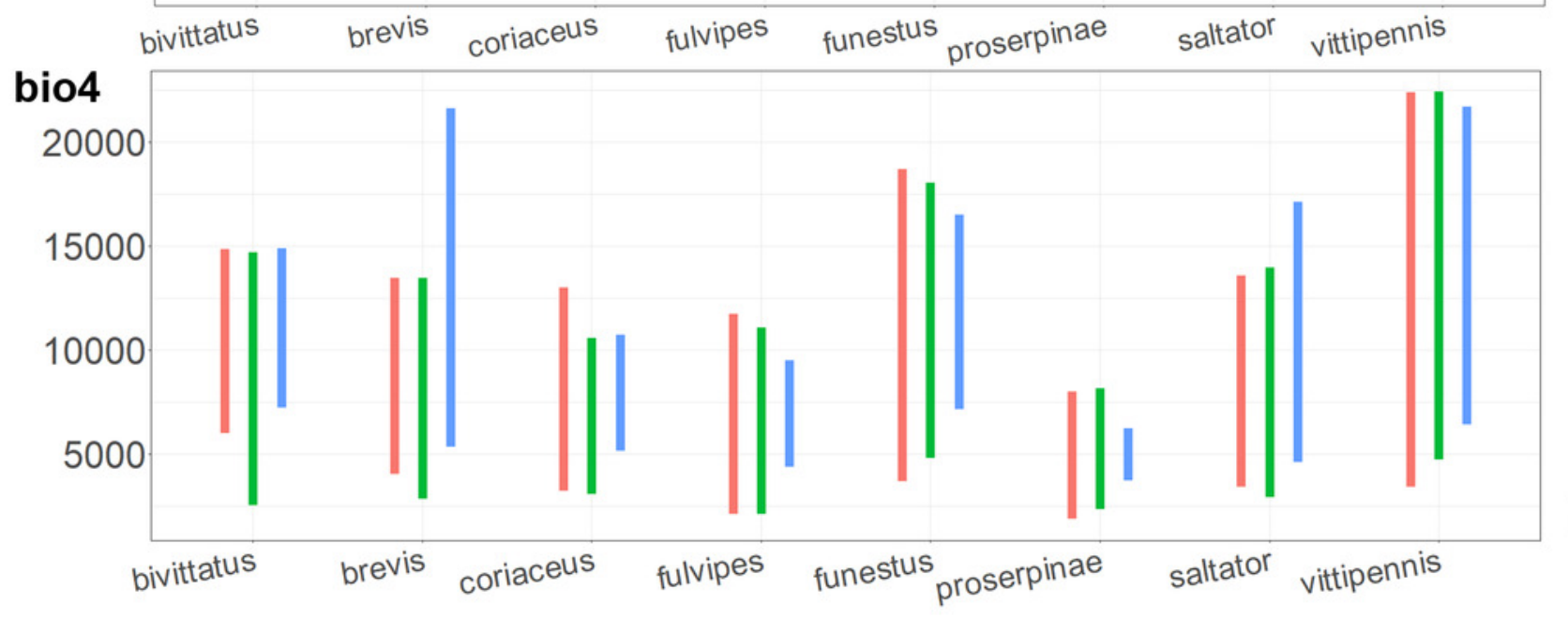

D 
Figure 8

The ranges of bio5, bio6, bio7, and bio8.

For each species, the first (red) line corresponds to the CF model, the second (green) line corresponds to the CR model, and the third (blue) line corresponds to the actual records. 

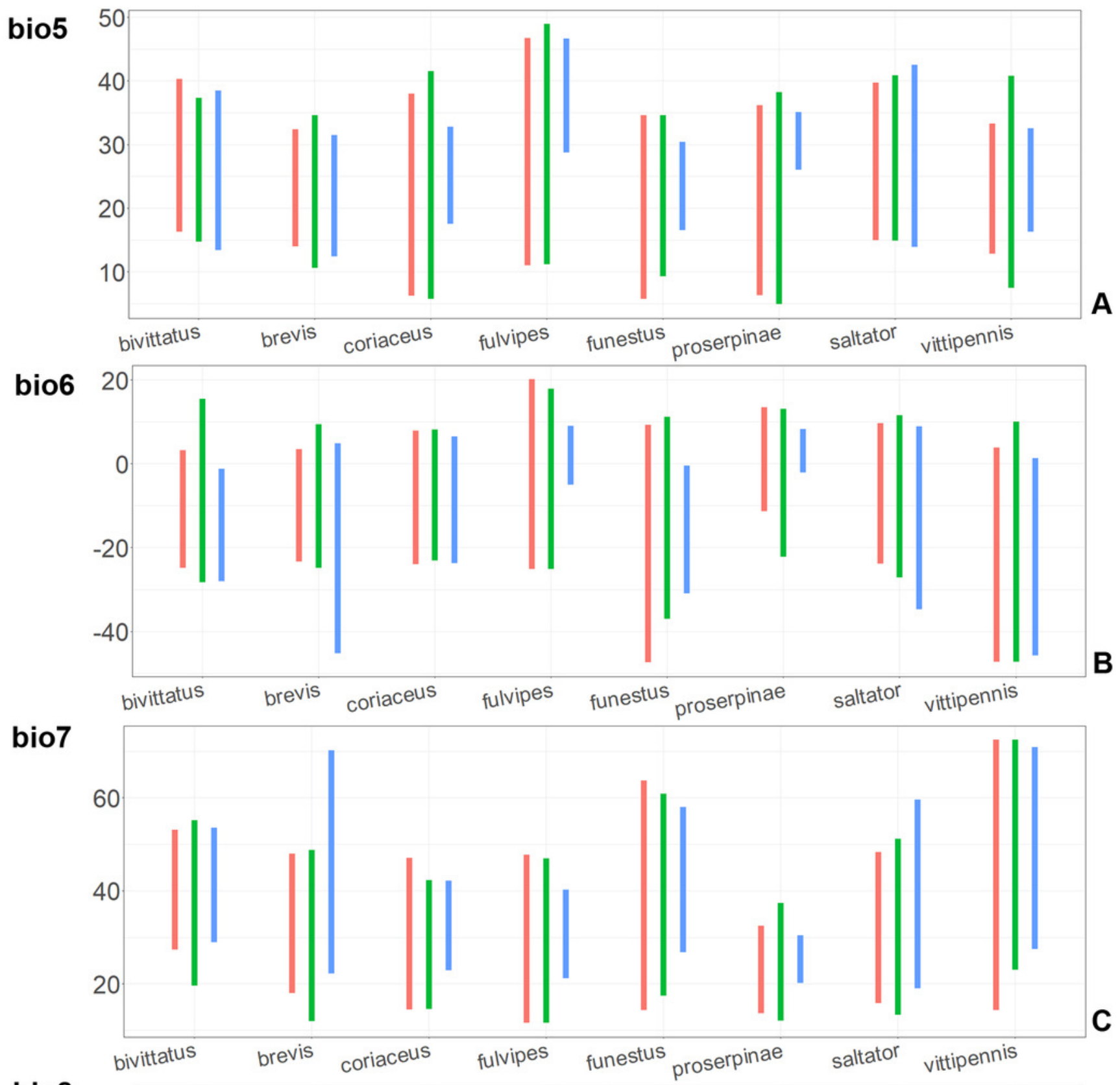

bio8

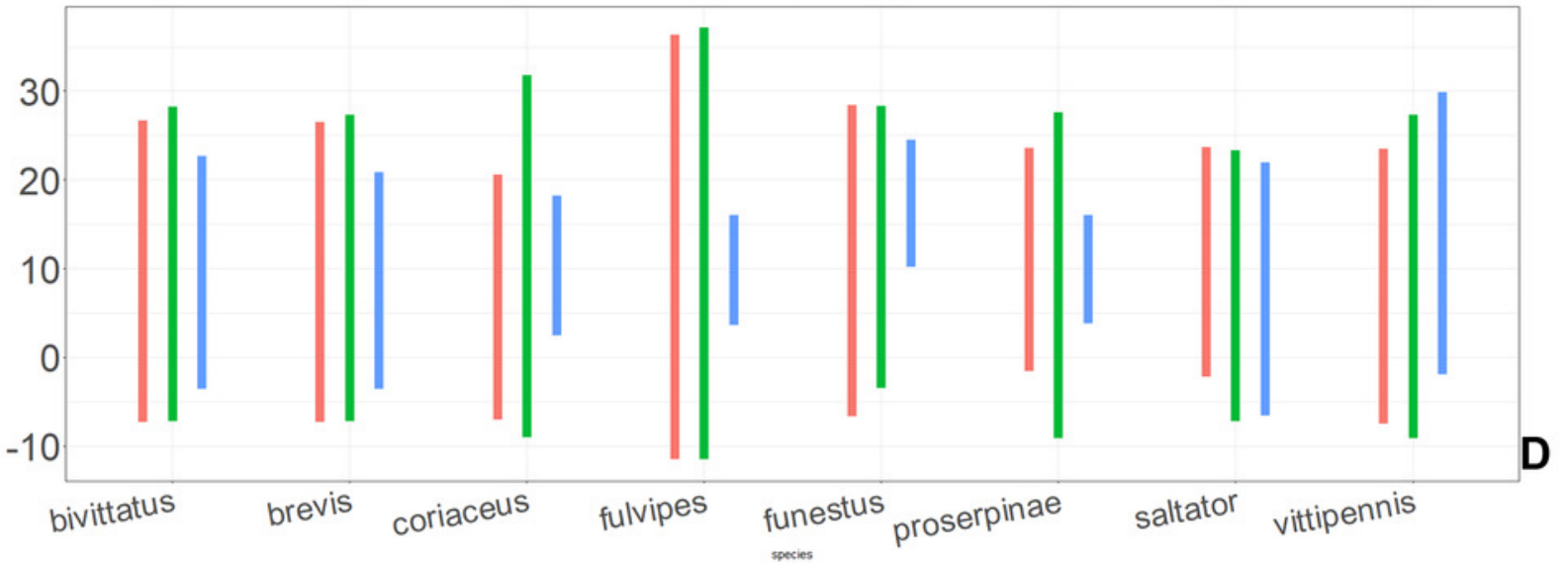


Figure 9

The ranges of bio9, bio10, bio11, and biol2.

For each species, the first (red) line corresponds to the CF model, the second (green) line corresponds to the CR model, and the third (blue) line corresponds to the actual records. 


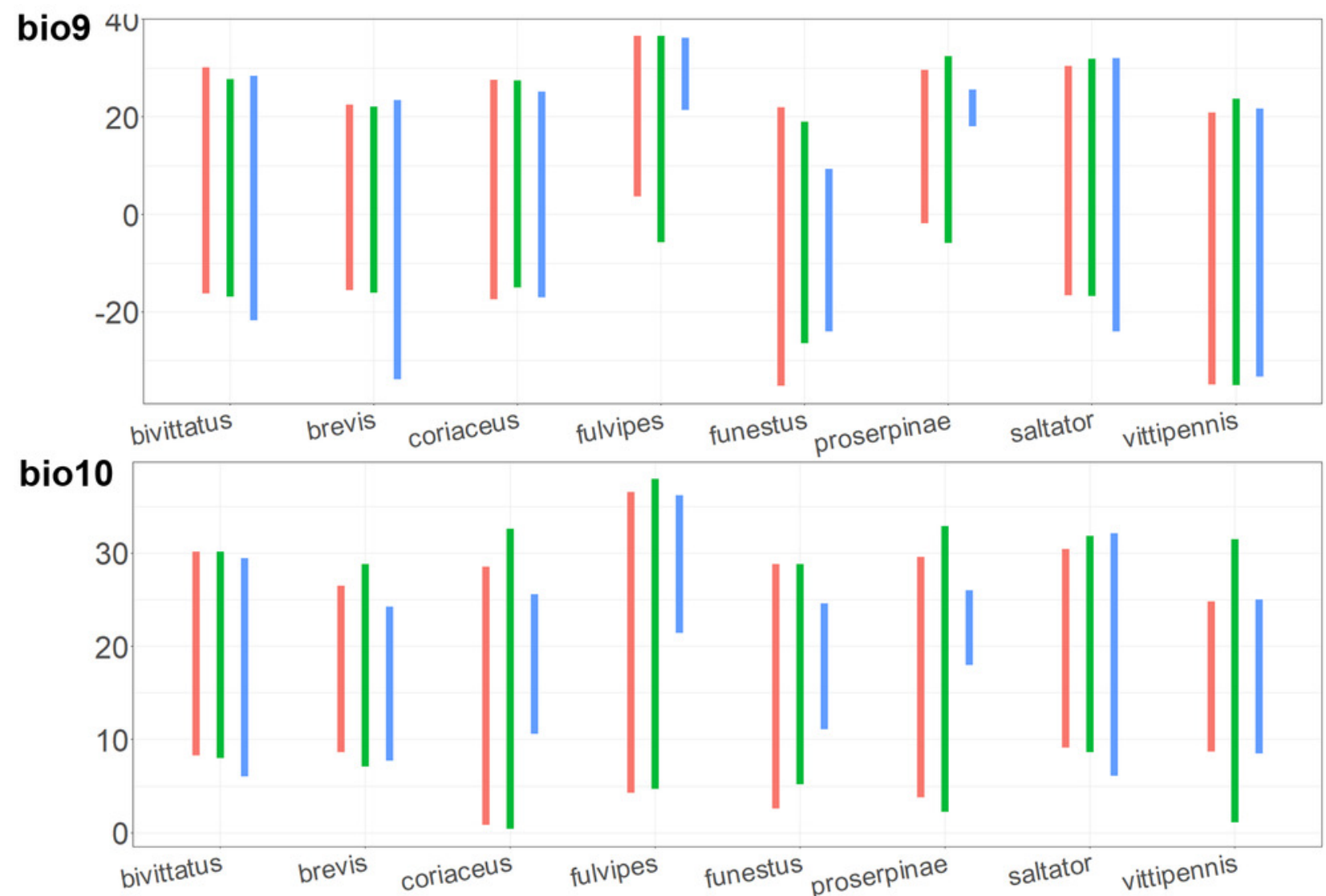

A

B

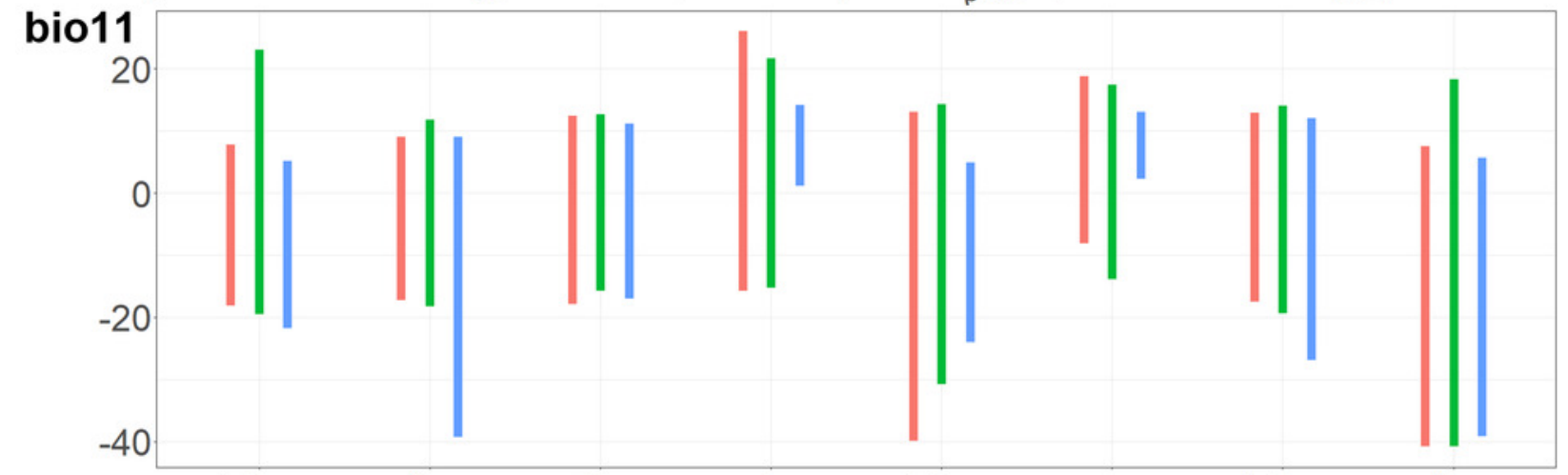

C

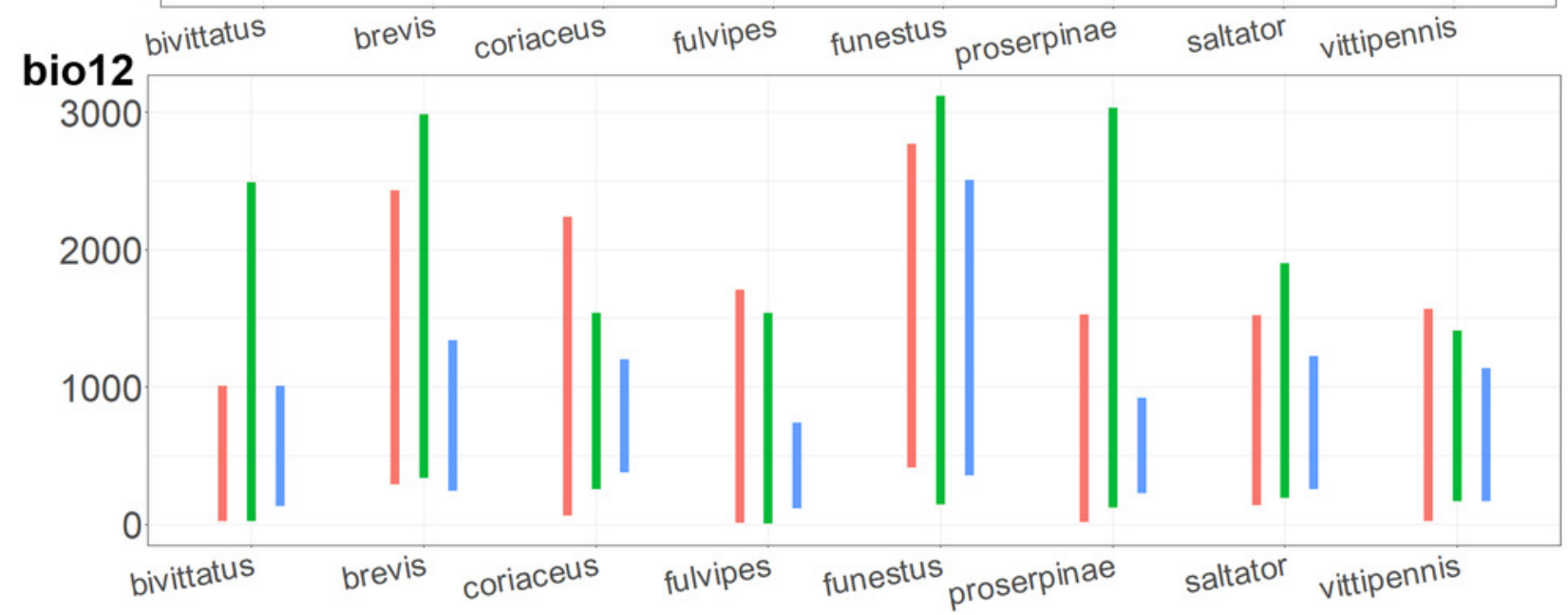

D 
Figure 10

The ranges of bio13, bio14, bio15, and bio16.

For each species, the first (red) line corresponds to the CF model, the second (green) line corresponds to the CR model, and the third (blue) line corresponds to the actual records. 


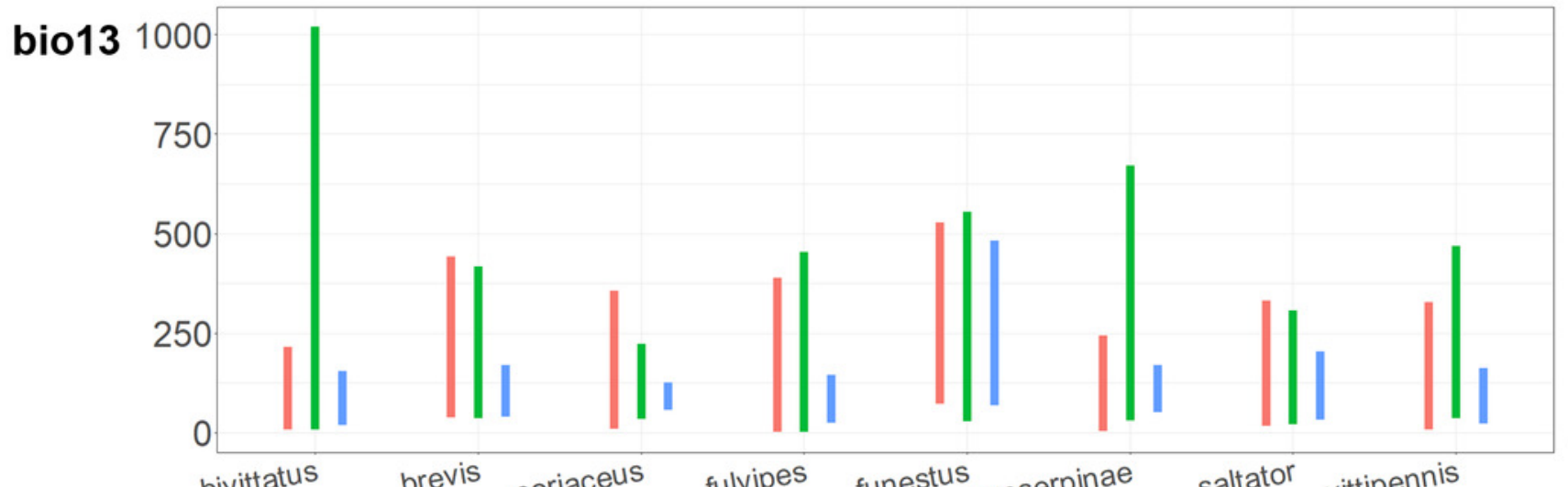

A bivittatus brevis coriaceus fulvipes funestus proserpinae saltator vittipennis

bio14

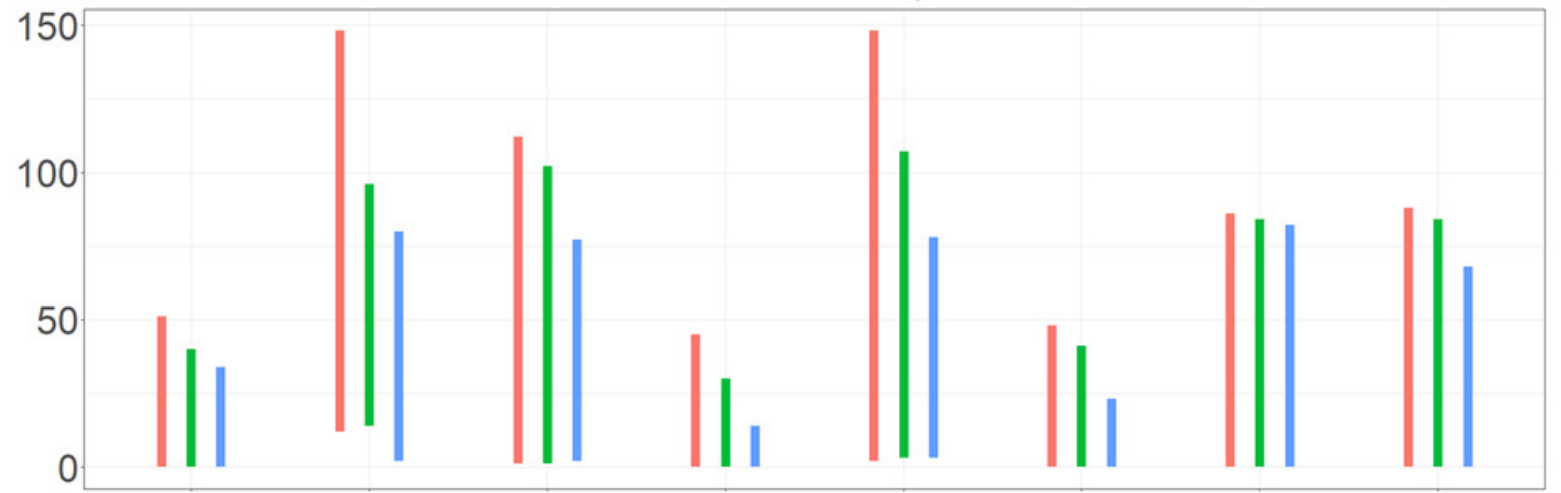

B bivittatus brevis coriaceus fulvipes funestus proserpinae saltator vittipennis

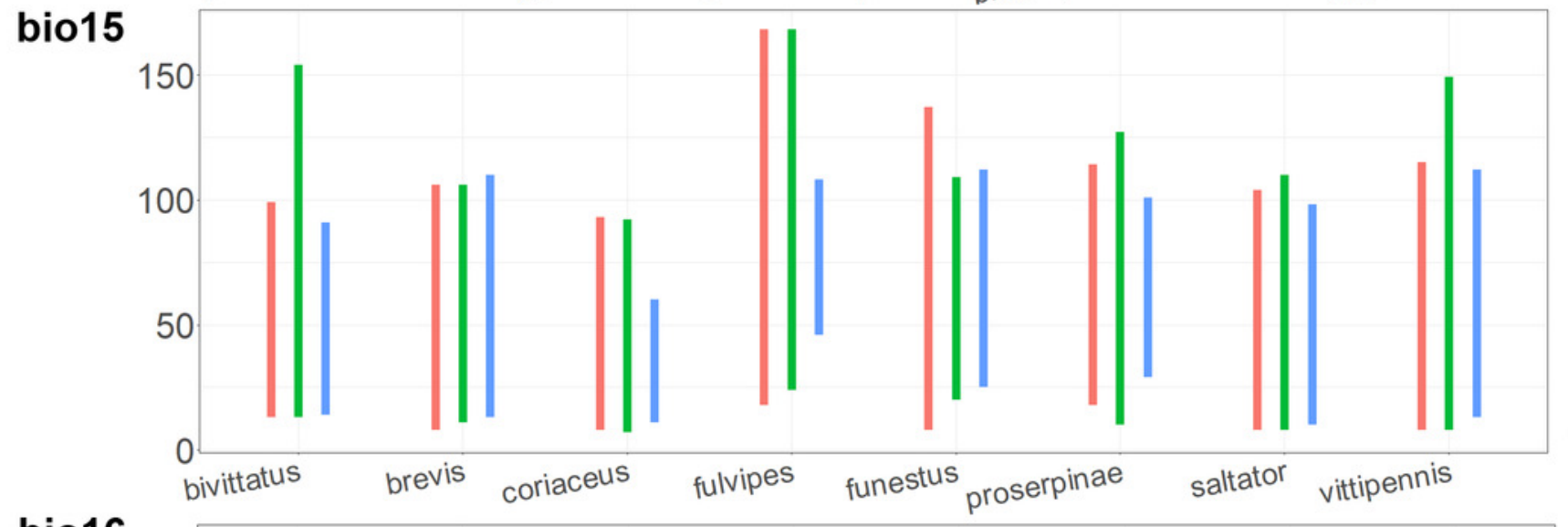

bio16

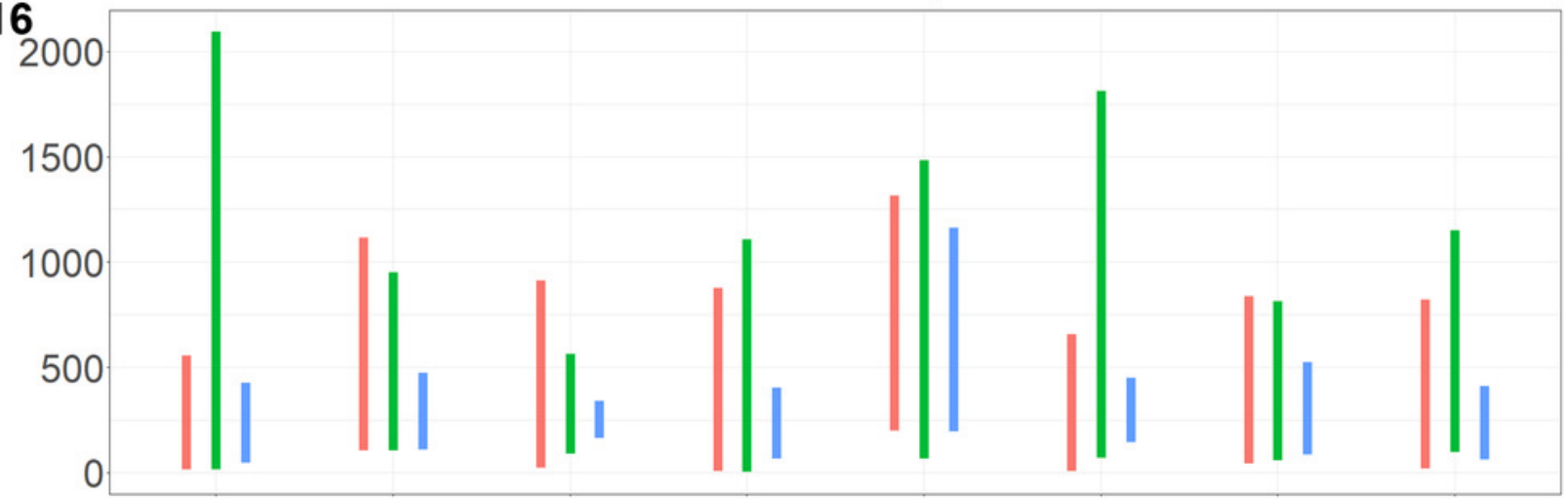

bivittatus brevis coriaceus fulvipes funestus proserpinae saltator vittipennis 
Figure 11

The ranges of bio17, bio18, bio19.

For each species, the first (red) line corresponds to the CF model, the second (green) line corresponds to the CR model, and the third (blue) line corresponds to the actual records. 


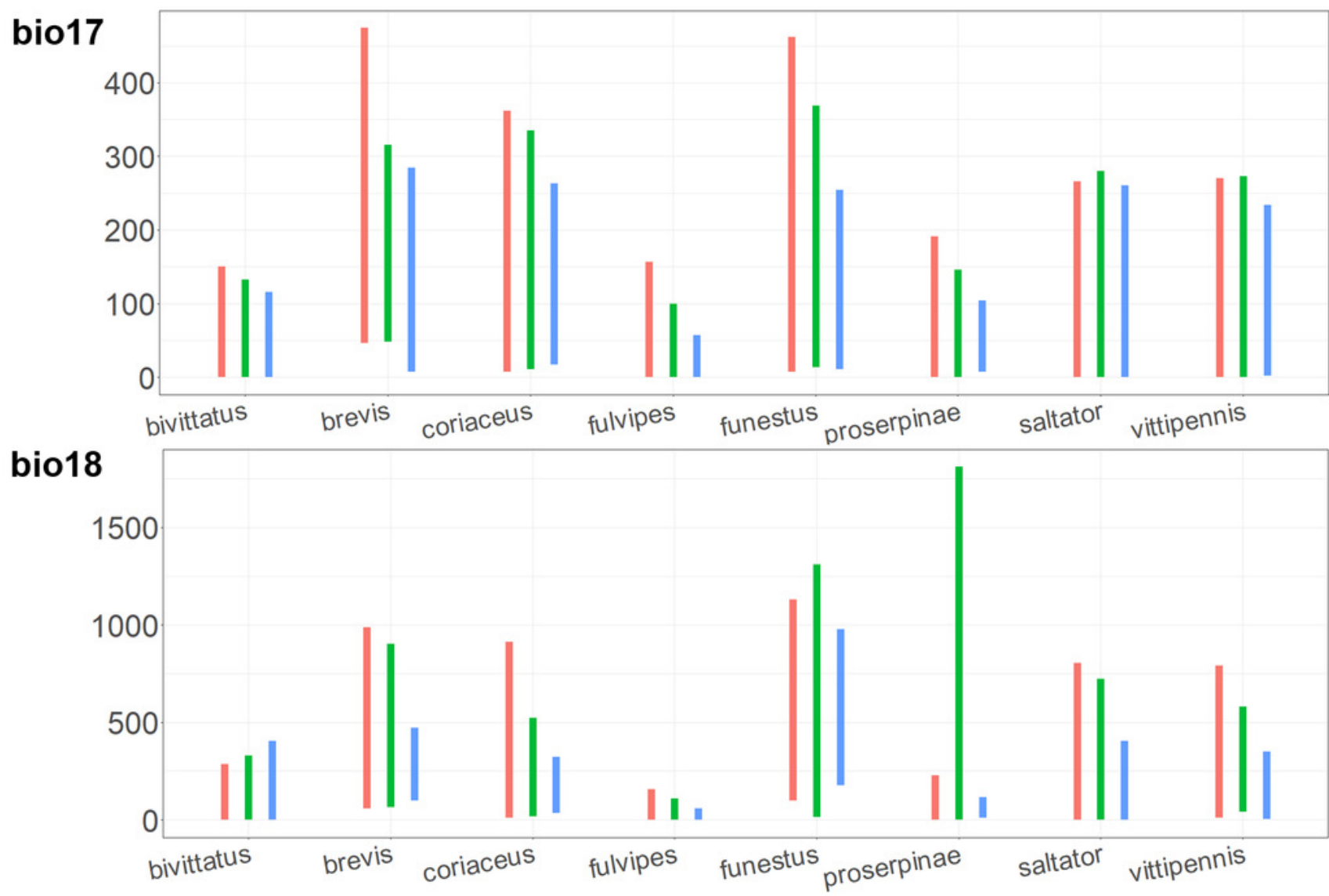

A

B

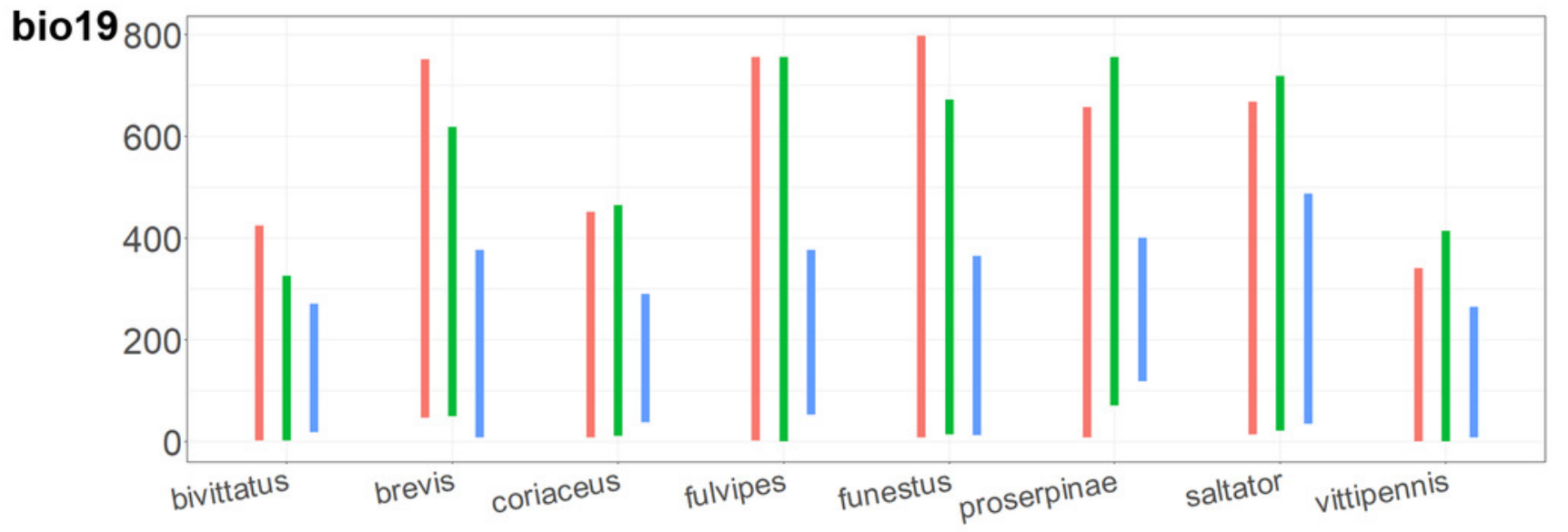

C 